\title{
Ionophore-Assisted Electrochemistry of Neutral Molecules: Oxidation of Hydrogen in an Ionic Liquid Electrolyte
}

\author{
Johannes Wandt, Junqiao Lee, Damien W. M. Arrigan, ${ }^{*}$ Debbie S. Silvester* \\ Curtin Institute for Functional Molecules and Interfaces, School of Molecular and Life Sciences, Curtin University, \\ GPO Box U1987, Perth, WA 6845, Australia. \\ * Email: D.Silvester-Dean@curtin.edu.au; Tel: +61-8-9266-7148 \\ *E-mail: D.Arrigan@curtin.edu.au; Tel: +61-8-9266-9735
}

\begin{abstract}
The electrochemical properties of gas molecules are of great interest for both fundamental and applied research. In this study, we introduce a novel concept to systematically alter the electrochemical behavior and, in particular, the redox potential of neutral gas molecules. The concept is based on the use of an ionbinding agent, or 'ionophore', to bind and stabilize the ionic electrochemical reaction product. We demonstrate that the ionophore-assisted electrochemical oxidation of hydrogen in a room temperature ionic liquid electrolyte is shifted by almost $1 \mathrm{~V}$ towards more negative potentials in comparison to an ionophore-free electrolyte. The altered electrochemical response in the presence of the ionophore not only yields insights into the reaction mechanism but can be used also to determine the diffusion coefficient of the ionophore species. This ionophore-modulated electrochemistry of neutral gas molecules opens up new avenues for the development of highly selective electrochemical sensors.
\end{abstract}

\section{Keywords:}

Cyclic voltammetry • Electrochemistry $\bullet$ Hydrogen $\bullet$ Ionic liquids $\bullet$ Ionophore 
The electrochemical oxidation and reduction of gas molecules at an electrode surface in liquid electrolytes is of great interest both for the understanding of fundamental electrochemical concepts and for technological applications, e.g. in the fields of electrochemical sensors ${ }^{1}$ and electrochemical energy systems. ${ }^{2}$ In this respect, the hydrogen oxidation reaction (HOR) and the oxygen reduction reaction (ORR) in particular have attracted a lot of attention in recent years. In general, electrochemical reactions are influenced by choice of the electrolyte solvent and conducting salt. For example, in the ORR, oxygen is reduced to water in aqueous media ( $4 \mathrm{e}^{-}$transfer), whereas it is reduced to peroxide in aprotic polar solvents containing hard Lewis acids as conducting salts ( $2 \mathrm{e}^{-}$transfer) and to superoxide in aprotic room temperature ionic liquids (RTILs) $\left(1 \mathrm{e}^{-}\right.$transfer). ${ }^{3}$ While electrolyte properties can be used to modulate electrochemical reactions in a favorable way, interactions with reaction intermediates and products are rather unspecific. In contrast, in a seminal publication, Shao-Horn and co-workers tailored an anion receptor which specifically binds to one target ion only. ${ }^{4}$ In this case, the hexacarboxamide cryptand specifically favored peroxide over the superoxide anion, which entirely changed the ORR mechanism. This work clearly shows that selective complexation of an ionic reaction product is an elegant way to alter an electrochemical reaction in a desired way and is a logical extension of electrode reactions with coupled chemical reactions. Nevertheless, to the best of our knowledge, no study has reported the use of an ion receptor to target a specific ionic product formed by the electrochemical reaction of a neutral gas molecule. This might be due, partly, to the tedious work required in the design and synthesis of ion receptors. Fortunately, the field of electrochemical sensors provides vast knowledge relating to ion selective receptors. The ion detection capability of sensors, such as the well-known potentiometric ion selective electrode (ISE), is based on assisted charge transfer across a phase boundary. ${ }^{5,6}$ Selectivity is achieved by facilitating this charge transfer with an ion selective receptor molecule, a so called 'ionophore'. A rich library of ionophores is available for a very broad range of target ions. ${ }^{6}$

The goal of this study is to investigate a new concept for electrochemical sensing of neutral gas molecules by exploiting ion-binding reagents, hereafter called 'ionophores', for reaction with a charged electrochemical reaction product. This binding is expected to shift the electrochemical reaction to lower or higher potentials, depending on the nature of the reaction; this shift in potential might be advantageous for applications such as amperometric gas sensing, e.g. enabling the detection reaction to be moved away from the reactions of interferences. The HOR was selected as a model reaction because it yields only ionic reaction products, namely protons, and because of its high technological importance. RTIL-based electrolytes were chosen for their practical advantages, including near-zero vapor pressure, intrinsic ionic conductivity, and, especially, the low coordinating capability of the RTIL anion (bis(trifluoromethylsulfonyl)imide, $\left[\mathrm{NTf}_{2}\right]^{-}$). The latter is a direct consequence of the charge delocalization in the S-N-S- backbone of the $\left[\mathrm{NTf}_{2}\right]^{-}$anion, which prevents competition with the ionophore for protonbinding. As well as the HOR, we also outline the limitations of the ionophore approach in more complex multi-electron reactions.

First, we briefly discuss the oxidation of $\mathrm{H}_{2}$ at a platinum disc electrode in carefully dried 1-ethyl-3methylimidazolium bis(trifluoromethylsulfonyl)imide $\left(\left[\mathrm{C}_{2} \mathrm{mim}\right]\left[\mathrm{NTf}_{2}\right]\right)$ without ionophore present. The respective voltammograms (Figure 1 a) largely agree with previous results in RTILs, showing single broad oxidative and reductive peaks with a peak-to-peak separation of $245 \mathrm{mV}$ at $100 \mathrm{vol}-\% \mathrm{H}_{2}{ }^{7-9}$ The reversibility increases with increasing $\mathrm{H}_{2}$ concentration and decreasing scan rate; this is probably a result of the higher proton concentration that facilitates the second order back reaction of: 


$$
\mathrm{H}_{2} \rightleftharpoons 2 \mathrm{H}^{+}+2 e^{-}
$$

Analysis of the peak current normalized by $\mathrm{H}_{2}$ concentration reveals that $\mathrm{H}_{2}$ pre-adsorption occurs and significantly contributes to the current amplitude at a low $\mathrm{H}_{2}$ concentration of $1 \%$ (see SI Figure S1). This is consistent with the report by Barrette and Sawyer for the aprotic HOR at platinum electrodes in a range of molecular aprotic solvents, ${ }^{10}$ and with the mechanism proposed by Tang et al. in ionic liquids. ${ }^{11}$ The quasi-steady-state-current observed at high overpotentials in the voltammograms for 10 and 50 vol- $\% \mathrm{H}_{2}$ also agrees well with expected diffusion limited current (see $\mathrm{SI}$ ), thus validating the experimental data. The potential of the oxidative peak varies from 0 to $150 \mathrm{mV}$ vs. the lithium iron phosphate (LFP) reference electrode ${ }^{12}$ which corresponds to 10 to $160 \mathrm{mV}$ vs ferrocene (see SI Figure S3). These values are slightly higher than in a previous report in which a peak position of $\sim-80 \mathrm{mV}$ vs. ferrocene was reported in the same RTIL. ${ }^{13}$ The more positive HOR potential in Figure $1 \mathrm{a}$ is probably a consequence of our rigorous solvent drying procedure as discussed below.
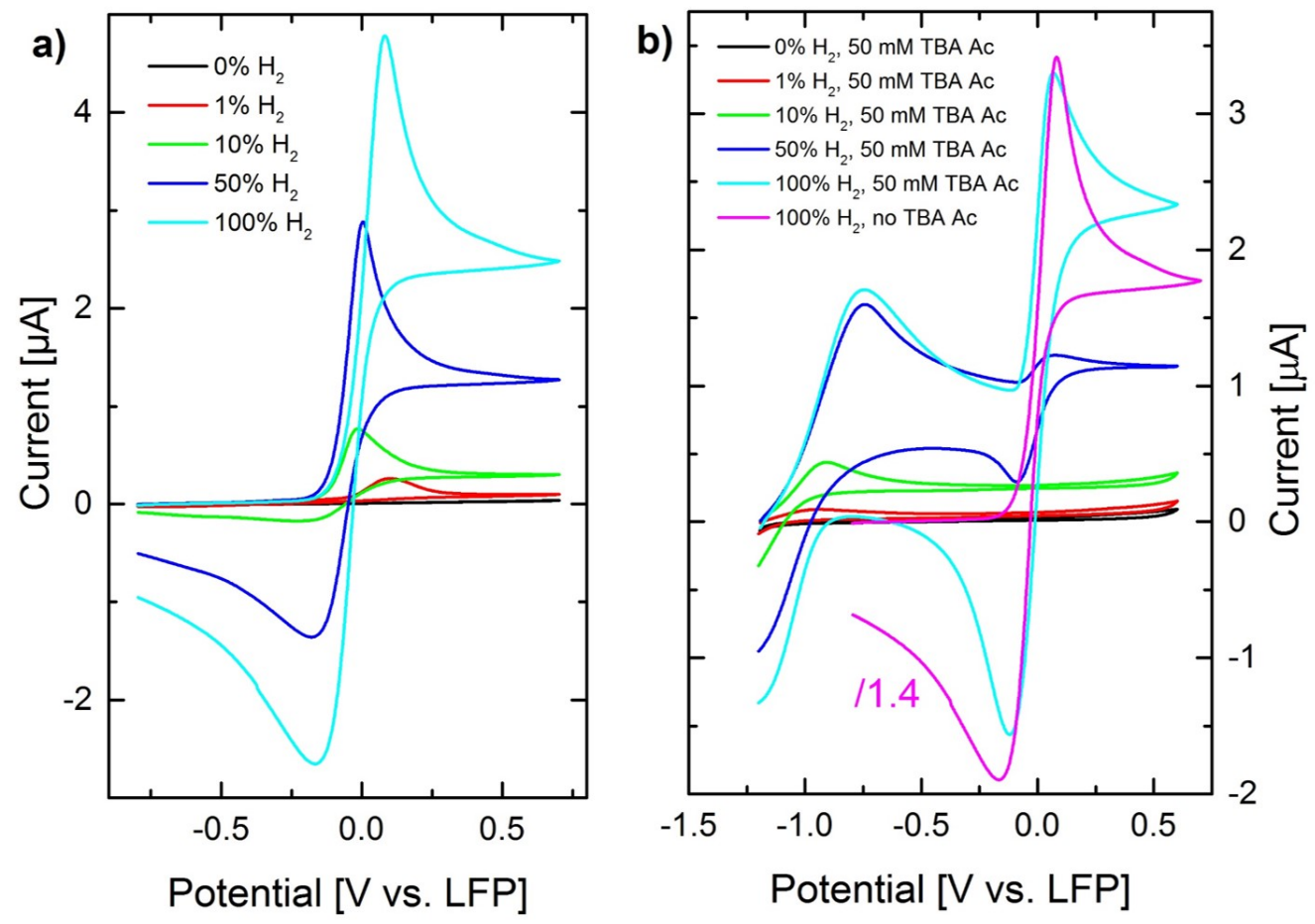

Figure 1 Cyclic voltammograms $\left(25 \mathrm{mVs}^{-1}\right)$ showing the hydrogen oxidation in $\left.\left[\mathrm{C}_{2} \mathrm{mim}\right]\left[\mathrm{NTf}_{2}\right] \mathrm{a}\right)$ in the absence and b) presence of $50 \mathrm{mM}$ TBA acetate for various hydrogen gas phase concentrations. Nitrogen makes up the remainder of the mixture. Pt disc, $1 \mathrm{~mm}$ diameter. The negative side of the potential window is limited by the reductive stability of the acetate anion (see discussion in the $\mathrm{SI}$ ).

Initial experiments showed that the $\mathrm{H}_{2}$ oxidation potential is highly dependent on the presence of residual water in the RTIL - the higher the water content, the lower the oxidation potential (see Figure S4). In pure and water-free ionic liquids, the generated proton (see equation 1 ) is only very poorly solvated by the $\left[\mathrm{NTf}_{2}\right]^{-}$anion, resulting in high oxidation potentials. Water, in contrast, is a much stronger base than the $\left[\mathrm{NTf}_{2}\right]^{-}$anion ${ }^{14,15}$ and can therefore effectively bind to, and stabilize, the generated protons according to:

$$
\mathrm{H}_{2}+2 \mathrm{H}_{2} \mathrm{O} \rightleftharpoons 2 \mathrm{H}_{3} \mathrm{O}^{+}+2 e^{-}
$$


resulting in lower oxidation potentials. To the best of our knowledge, the strong dependence of the $\mathrm{H}_{2}$ oxidation potential on the residual water content in RTILs has not yet been reported in the literature. This effect can be perceived as an example of our concept to influence a redox reaction by stabilizing the ionic product. However, water is known to readily solvate many types of cations and anions because of its high dipole moment, thus rendering its stabilizing effect rather unspecific. Therefore, all experiments in this study were carried out under strict water exclusion conditions (see experimental section for details).

We now consider the influence of acetate and another commercial ionophore on the electrochemical HOR. The acetate anion is a base of moderate strength (aqueous $\mathrm{p} K_{\mathrm{a}}$ of acetic acid $=4.76$ ) ${ }^{16}$ which is expected to bind to protons generated during the electrochemical $\mathrm{H}_{2}$ oxidation according to the following overall reaction:

$$
\mathrm{H}_{2}+2 \mathrm{Ac}^{-} \rightleftharpoons 2 \mathrm{HAc}+2 e^{-}
$$

which can also be perceived to be reaction (1) followed by:

$$
2 \mathrm{H}^{+}+2 \mathrm{Ac}^{-} \rightleftharpoons 2 \mathrm{HAc}
$$

We use acetate here as a simple ion-binding reagent, operating via an acid-base reaction to capture available protons, in the same manner as commercially available proton ionophores. Figure $1 \mathrm{~b}$ shows $\mathrm{H}_{2}$ oxidation in $\left[\mathrm{C}_{2} \mathrm{mim}\right]\left[\mathrm{NTf}_{2}\right]$ in the presence of $50 \mathrm{mM}$ tetrabutylammonium acetate (TBA Ac) for various $\mathrm{H}_{2}$ concentrations, from 1 to 100 vol-\%, at a scan rate of $25 \mathrm{mVs}^{-1}$ (for data at $500 \mathrm{mVs}^{-1}$ see SI). A cyclic voltammogram recorded in the absence of TBA Ac (pink curve, same data as Figure 1a) is also included. At $\mathrm{H}_{2}$ concentrations of 1 and 10 vol-\% (red and green curves), an oxidation peak appears at $-0.8 \mathrm{~V}$ vs LFP which is followed by a $\mathrm{H}_{2}$ diffusion limited current. In the absence of acetate, $\mathrm{H}_{2}$ oxidation is not possible within this potential range (see Figure 1a); accordingly, the $\mathrm{H}_{2}$ oxidation peak at $-0.8 \mathrm{~V}$ vs LFP can be assigned to the ionophore-assisted reaction (4). As no second oxidation peak occurs at higher potentials at $\mathrm{H}_{2}$ concentrations of 1 and 10 vol-\% (corresponding to $\mathrm{H}_{2}$ concentrations of 0.014 and $0.14 \mathrm{mmol} \mathrm{L}^{-1}$ in the RTIL), ${ }^{17}$ the acetate concentration at the electrode surface must be sufficiently high throughout the entire voltammogram to consume all generated protons.

At a $\mathrm{H}_{2}$ concentration of 50 vol-\% (dark blue curve), the oxidation peak at $-0.8 \mathrm{~V}$ is significantly larger and a second oxidation peak starts to emerge at ca. $0 \mathrm{~V}$ vs LFP. Based on its position (compared to the pink curve in Figure $2 \mathrm{~b}$ ), the second oxidation can be assigned to the oxidation of $\mathrm{H}_{2}$ in the absence of the acetate ionophore, according to equation (1). The depletion of the acetate ionophore at the electrode surface is caused by its much slower diffusion in comparison to molecular $\mathrm{H}_{2}$. The reason for this is the larger size and the negative charge of the acetate anion, two factors which slow down diffusion in RTILs. ${ }^{18}$ Note that at potentials above $0 \mathrm{~V}$ vs LFP, the ionophore assisted reaction (4) continues (controlled by acetate diffusion towards the electrode surface) in parallel with reaction (1), which consumes surplus $\mathrm{H}_{2}$ at the electrode surface.

At a $\mathrm{H}_{2}$ concentration of 100 vol-\% (cyan curve), the oxidation peak at $-0.8 \mathrm{~V}$ vs LFP has a similar current as 50 vol-\%. This confirms that at high $\mathrm{H}_{2}$ 'concetrations, it is not $\mathrm{H}_{2}$ but acetate diffusion towards the electrode surface that limits the ionophore-assisted $\mathrm{H}_{2}$ oxidation. The second oxidation peak at ca. $0 \mathrm{~V}$ vs. LFP is significantly higher than for 50 vol-\% in the presence of acetate (dark blue curve), but still smaller than the same oxidation peak at $\mathrm{H}_{2}$ concentration of 100 vol-\% in the absence of the acetate ionophore (pink curve). 
Let us now take a closer look at the reduction peak at about $-0.15 \mathrm{~V}$ vs LFP (Figure $1 \mathrm{~b}$ ) which can be assigned to the reduction of "free" protons (reversal of reaction 1). At 100 vol- $\% \mathrm{H}_{2}$, this reduction peak is very high due to the large amount of free protons formed in the preceding oxidative scan, while it is entirely absent at a $\mathrm{H}_{2}$ concentrations of 1 and $10 \%$. At 50 vol- $\% \mathrm{H}_{2}$, a clear reduction peak is visible at $0.15 \mathrm{~V}$ vs LFP while the overall current is still positive, i.e. oxidative. This can be interpreted as a superposition of the ionophore-assisted $\mathrm{H}_{2}$ oxidation (reaction 4) with the simultaneous reduction of free protons (reverse of reaction 1 ). The rate of the former reaction must slightly exceed the rate of the latter in order to obtain an overall oxidative current. Accordingly, the voltammetric shapes shown in Figure $1 \mathrm{~b}$ can be simulated by a combination of reactions 1 and 4 (see Figure $S 5$ and discussion in the supporting information).

Below $-0.8 \mathrm{~V}$ vs. LFP, the onset of the HAc reduction (reverse of reaction 3 ) can be observed. Due to the limited reductive stability of the acetate ionophore, scanning through the full HAc reduction peak was avoided to prevent fouling of the working electrode (see discussion in the SI). Nevertheless, it appears that the peak-to-peak separation of this reaction is greater than that of the ionophore-free process, suggesting that the former has slower electrode kinetics.

From the separation of the formal redox potential $E^{\circ \prime}$ values of reactions (1) and (4), it is possible to estimate the Gibbs free energy of the proton binding by the acetate ionophore according to:

$$
\Delta G=-z_{e} F \Delta E^{0 \prime}
$$

where $z_{e}$ is the number of electrons transferred per hydrogen molecule $(=2), F$ is the Faraday constant and $\Delta E^{O \prime}$ is the difference between the formal potentials for reactions (1) and (4) (the formal potentials are taken as the average of the oxidative and reductive peak potentials for each process). Unfortunately, the formal potential for reaction (4) cannot be precisely determined as its reduction peak is not fully resolved but it can be estimated that $\Delta E^{0^{\prime}} \geq 1 \mathrm{~V}$ (from Figure $1 \mathrm{~b}$ ), resulting in a Gibbs free energy for acetate-proton binding of $<-200 \mathrm{~kJ} \mathrm{~mol}^{-1}$. This value for acetate-proton binding can be compared to $-53 \mathrm{~kJ} \mathrm{~mol}^{-1}$ in water (based on an aqueous $p K_{\mathrm{a}}$ of 4.76 ) and $-1400 \mathrm{~kJ} \mathrm{~mol}^{-1}$ in the gas phase, ${ }^{19}$ and is a consequence of the comparably weak solvation of ionic species (i.e. acetate and protons) in RTILs compared to a high dielectric solvent like water.

Based on the acetate diffusion limited current for 50 and 100 vol-\% $\mathrm{H}_{2}$ (Figure $1 \mathrm{~b}$ ), the diffusion coefficient of acetate, $D\left(\mathrm{Ac}^{-}\right)$was estimated to be $\sim 3 \times 10^{-8} \mathrm{~cm}^{2} \mathrm{~s}^{1}$ (see $\mathrm{SI}$ for details). To the best of our knowledge, this is the first experimental determination of a diffusion coefficient of a carboxylate anion in RTILs. The reported value of $D\left(\mathrm{Ac}^{-}\right)$is smaller by a factor of about three than the diffusion coefficients reported for chloride $^{20}$ and superoxide anions ${ }^{21}$ (both $D=1.1 \times 10^{-7} \mathrm{~cm}^{2} \mathrm{~s}^{1}$ ) in similar RTILs, which is a consequence of the larger size of the acetate anion. The ionophore-assisted electrochemistry concept is an interesting option for the indirect determination of the diffusion coefficients of molecules such as the acetate anion, which might otherwise be hindered by complex electrode reactions. 


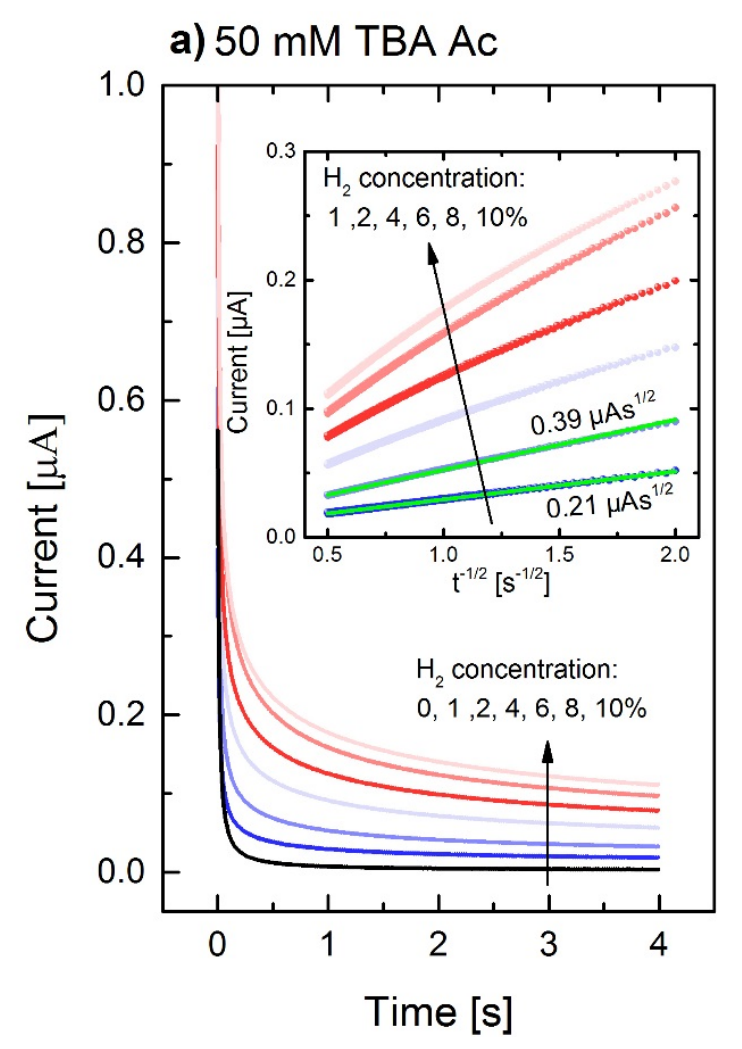

\section{b) no TBA Ac}

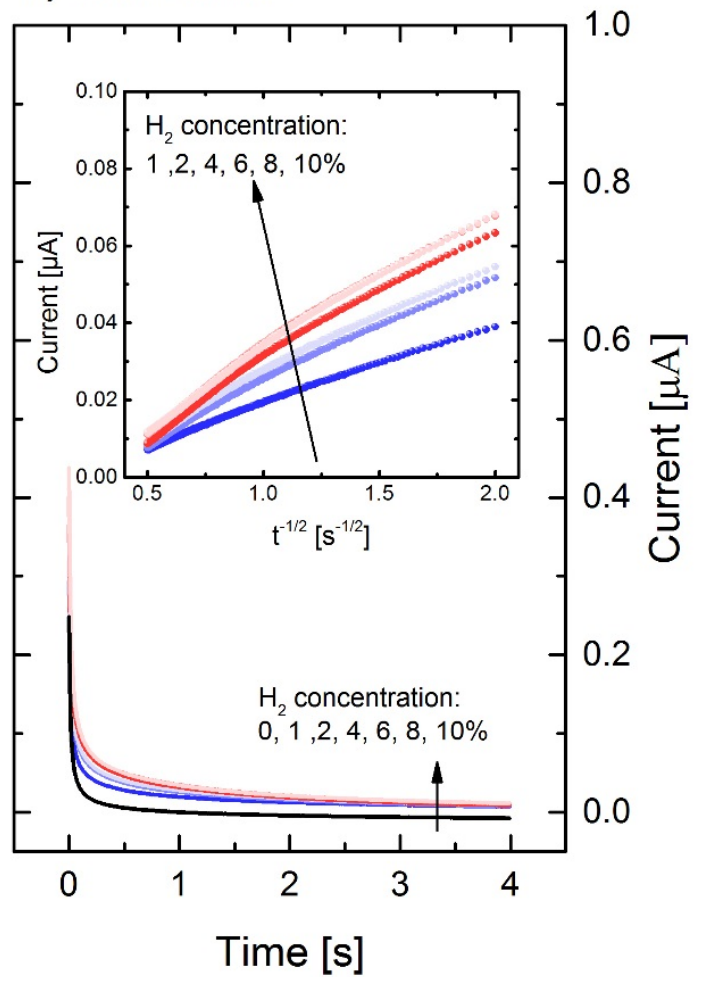

Figure 2 Current transients recorded after stepping the potential from -1.2 to $-0.35 \mathrm{~V}$ vs LFP in $\left[\mathrm{C}_{2} \mathrm{mim}\right]\left[\mathrm{NTf}_{2}\right]$ in the presence (a) and absence (b) of $50 \mathrm{mM}$ TBA acetate for various hydrogen gas phase concentrations. The inset shows the linearized plot based on the Cottrell equation; note that the first 250 ms were omitted in the linearized plot because of double layer charging effects.

A possible practical application for the ionophore-assisted concept is to lower the oxidation potential (or magnitude of the reduction potential) of the targeted analyte to avoid cross-sensitivities which are a major obstacle for electrochemical gas sensors. ${ }^{22}$ Figure 2a shows a chronoamperometric experiment in the presence of $50 \mathrm{mM}$ TBA Ac. First, the potential was held at $-1.2 \mathrm{~V}$ vs. LFP (the open circuit potential in the presence of TBA Ac and $\mathrm{H}_{2}$ ) for a few seconds and then stepped up to $-0.350 \mathrm{~V}$ vs LFP for four seconds while current transients were recorded. A potential of $-0.350 \mathrm{~V}$ vs LFP was chosen so that the acetateassisted HOR (equation 4) is in a diffusion-limited regime while the unassisted HOR (equation 1 ) does not occur (see Figure $1 \mathrm{~b}$ ). As expected, the current increases with $\mathrm{H}_{2}$ concentration as shown in Figure $2 \mathrm{a}$, yielding a linear dependence of current on the hydrogen concentration, $i(A)=1.0 \times 10^{-8}\left(\mathrm{~A} / \mathrm{vol}-\% \mathrm{H}_{2}\right) . c$ $\left(\right.$ vol- $\left.\% \mathrm{H}_{2}\right)+1.2 \times 10^{-8}(\mathrm{~A}), \mathrm{R}^{2}=0.991$. Diffusion controlled current transients in a potential step experiment at a $\mathrm{mm}$-sized disk electrode can be described by the Cottrell equation ${ }^{23}$

$$
i=\frac{z_{e} F A c_{j}^{0} \sqrt{D_{j}}}{\sqrt{\pi} \sqrt{t}}
$$

where $z_{e}$ is the number of electrons, $F$ is the Faraday constant, $A$ is the electrode area, $c^{0}$ is the initial bulk concentration and $D$ is the diffusion coefficient, $t$ is the time; the index $j$ refers to the redox active species, in this case $\mathrm{H}_{2}$. The experimental current transients for 1 and 2 vol- $\% \mathrm{H}_{2}$ in the presence of acetate nicely follow the Cottrell equation, but above 2 vol- $\% \mathrm{H}_{2}$, the experimental current transients increasingly fall below the values predicted by the Cottrell equation (see Figure S6). The linearized plot of the Cottrell equation (inset Figure $2 \mathrm{a}$ ) also shows that the ratio of the slopes for 1 and 2 vol- $\% \mathrm{H}_{2}$ come close to the 
expected value of 2 , while the transients cannot be properly linearized for higher $\mathrm{H}_{2}$ concentrations. This means that for up to 2 vol-\% $\mathrm{H}_{2}$, the acetate concentration at the electrode surface is high enough to ensure that only $\mathrm{H}_{2}$ diffusion is rate limiting, whereas at higher $\mathrm{H}_{2}$ concentrations the availability of acetate at the electrode surface also starts to affect the rate. In the absence of the ionophore, the current transients at a constant potential of $-0.35 \mathrm{~V}$ vs LFP are much smaller and also do not depend on the $\mathrm{H}_{2}$ concentration (Figure 2b). This shows that the ionophore-assisted electrochemistry concept can be used to effectively change the potential window in which an analyte can be detected.

We also investigated the HOR using hydrogen ionophore IV (see Figure S7), a commercial pyridine-based hydrogen ionophore that interacts with protons in an acid-base reaction. Qualitatively, the results were similar to the acetate ionophore results, but the intensities of the ionophore-assisted $\mathrm{H}_{2}$ oxidation peaks were much lower due to the lower diffusion coefficient of hydrogen ionophore IV and its lower solubility. We are planning to extend the ionophore-assisted electrochemistry concept to other reactions - such as the electrochemical reduction of chlorine gas to chloride anions ${ }^{24}$ and the more complex iodine/iodide/triiodide system ${ }^{25}$ - and to investigate the limitations of the ionophore concept. Our preliminary data for the oxidation of ammonia, which produces ammonium cations (see Figure S8), suggests that the concept may not be usefully applied for such a complex multi-electron reaction. As a result, future work will elucidate the exact criteria that render electrochemical reactions of neutral gas molecules susceptible to the influence of ionophores.

In conclusion, we have shown that by addition of an ion-binding reagent (ionophore) to the electrolyte solution, the oxidation of a neutral gas molecule can be shifted to lower potentials by virtue of the binding of the ionized electrochemical reaction product. This capability opens up prospects for the use of such ionophores to modulate the electrochemistry of gases, including tuning the sensitivity and selectivity of amperometric gas sensors. The design of ionophores that specifically bind to electrochemical reaction products and which possess good solubility in the chosen electrolyte medium will greatly improve the expansion of this line of investigation.

\section{Supporting Information Available:}

Experimental description, evidence of hydrogen pre-adsorption on the working electrode, reference electrode choice, estimation of diffusion limited current and acetate diffusion coefficient. Influence of water impurities, Cottrell behaviour of current transients, simulation of cyclic voltammograms, and behaviour with commercial hydrogen ionophore IV and ammonia oxidation. This material is available free of charge via the Internet at http://pubs.acs.org.

The authors declare no competing financial interest.

\section{Acknowledgements}

J.W. gratefully acknowledges the support of a German Academic Exchange Service (DAAD) scholarship. D.S.S. thanks the Australian Research Council for a Future Fellowship (FT170100315). 


\section{References}

(1) Hahn, C. E. W. Tutorial Review Electrochemical Analysis of Clinical Blood-Gases, Gases and Vapours. Analyst 1998, 123 (June), 57-86.

(2) Carrette, L.; Friedrich, K. A.; Stimming, U. Fuel Cells : Principles, Types, Fuels, and Applications. Chem. Phys. Phys. Chem. 2000, 1, 162-193.

(3) Sawyer, D. T. Oxygen Chemistry; Oxford University Press: New York, 1991.

(4) Lopez, N.; Graham, D. J.; McGuire, R.; Alliger, G. E.; Shao-Horn, Y.; Cummins, C. C.; Nocera, D. G. Reversible Reduction of Oxygen to Peroxide Facilitated by Molecular Recognition. Science 2012, 335 (6067), 450-453.

(5) Bakker, E.; Pretsch, E. Modern Potentiometry. Angew. Chemie Int. Ed. 2007, 46, 5660-5668.

(6) BühImann, P.; Pretsch, E.; Bakker, E. Carrier-Based Ion-Selective Electrodes and Bulk Optodes . 2. Ionophores for Potentiometric and Optical Sensors. Chem. Rev. 1998, 2665 (97), 1593-1688.

(7) Silvester, D. S.; Aldous, L.; Hardacre, C.; Compton, R. G. An Electrochemical Study of the Oxidation of Hydrogen at Platinum Electrodes in Several Room Temperature lonic Liquids. J. Phys. Chem. $B$ 2007, 111 (18), 5000-5007.

(8) Silvester, D. S.; Ward, K. R.; Aldous, L.; Hardacre, C.; Compton, R. G. The Electrochemical Oxidation of Hydrogen at Activated Platinum Electrodes in Room Temperature lonic Liquids as Solvents. J. Electroanal. Chem. 2008, 618 (1-2), 53-60.

(9) Sandoval, A. P.; Suárez-Herrera, M. F.; Feliu, J. M. Hydrogen Redox Reactions in 1-Ethyl-2,3Dimethylimidazolium Bis(Trifluoromethylsulfonyl)Imide on Platinum Single Crystal Electrodes. Electrochem. commun. 2014, 46, 84-86.

(10) Barrette, W. C.; Sawyer, D. T. Determination of Dissolved Hydrogen and Effects of Media and Electrode Materials on the Electrochemical Oxidation of Molecular Hydrogen. Anal. Chem. 1984, 56 (4), 653-657.

(11) Tang, Y.; Zeng, X. Electrochemical Oxidation of Hydrogen in Bis(Trifluoromethylsulfonyl)Imide Ionic Liquids under Anaerobic and Aerobic Conditions. J. Phys. Chem. C 2017, 41 (120), 2354223551.

(12) Wandt, J.; Lee, J.; Arrigan, D. W. M.; Silvester, D. S. A Lithium Iron Phosphate Reference Electrode for Ionic Liquid Electrolytes. Electrochem. commun. 2018, 93 (June), 148-151.

(13) Meng, Y.; Aldous, L.; Belding, S. R.; Compton, R. G. The Formal Potentials and Electrode Kinetics of the Proton/Hydrogen Couple in Various Room Temperature Ionic Liquids. Chem. Commun. 2012, 48 (45), 5572.

(14) Thomazeau, C.; Olivier-Bourbigou, H.; Magna, L.; Luts, S.; Gilbert, B. Determination of an Acidic Scale in Room Temperature Ionic Liquids. J. Am. Chem. Soc. 2003, 125, 5264-5265.

(15) Chiappe, C.; Pieraccini, D. Ionic Liquids: Solvent Properties and Organic Reactivity. J. Phys. Org. Chem. 2005, 18 (4), 275-297.

(16) Rumble, J. CRC Handbook of Chemistry and Physics, 98th Edition; 2017.

(17) Lei, Z.; Dai, C.; Chen, B. Gas Solubility in Ionic Liquids. Chem. Rev. 2014, 114 (2), 1289-1326. 
(18) Barrosse-Antle, L. E.; Bond, A. M.; Compton, R. G.; O’Mahony, A. M.; Rogers, E. I.; Silvester, D. S. Voltammetry in Room Temperature lonic Liquids: Comparisons and Contrasts with Conventional Electrochemical Solvents. Chem. - An Asian J. 2010, 5 (2), 202-230.

(19) Cumming, J. P.; Kebarle, P. Summary of Gas Phase Acidity Measurements Involving Acids AH. Entropy Changes in Proton Transfer Reactions Involving Negative lons. Bond Dissociation Energies $\mathrm{D}(\mathrm{A}-\mathrm{H})$ Abd Electron Affinities EA(A). Can. J. Chem. 1978, 56 (1), 1-9.

(20) Villagrán, C.; Banks, C. E.; Hardacre, C.; Compton, R. G. Electroanalytical Determination of Trace Chloride in Room-Temperature lonic Liquids. Anal. Chem. 2004, 76 (7), 1998-2003.

(21) Herranz, J.; Garsuch, A.; Gasteiger, H. A. Using Rotating Ring Disc Electrode Voltammetry to Quantify the Superoxide Radical Stability of Aprotic Li-Air Battery Electrolytes. J. Phys. Chem. C 2012, 116 (36), 19084-19094.

(22) Silvester, D. S. New Innovations in Ionic Liquid-Based Miniaturised Amperometric Gas Sensors. Curr. Opin. Electrochem. 2019, 15, 7-17.

(23) Bard, A. J.; Faulkner, L. R. Electrode Reactions with Coupled Homogeneous Chemical Reactions. In Electrochemical Methods Fundamentals ad Applications; 2011; p 471.

(24) Murugappan, K.; Arrigan, D. W. M.; Silvester, D. S. Electrochemical Behavior of Chlorine on Platinum Microdisk and Screen-Printed Electrodes in a Room Temperature Ionic Liquid. J. Phys. Chem. C 2015, 119 (41), 23572-23579.

(25) Zhao, Y.; Wang, L.; Byon, H. R. High-Performance Rechargeable Lithium-lodine Batteries Using Triiodide/lodide Redox Couples in an Aqueous Cathode. Nat. Commun. 2013, 4 (May), 18961897. 


\section{TOC Graphic}

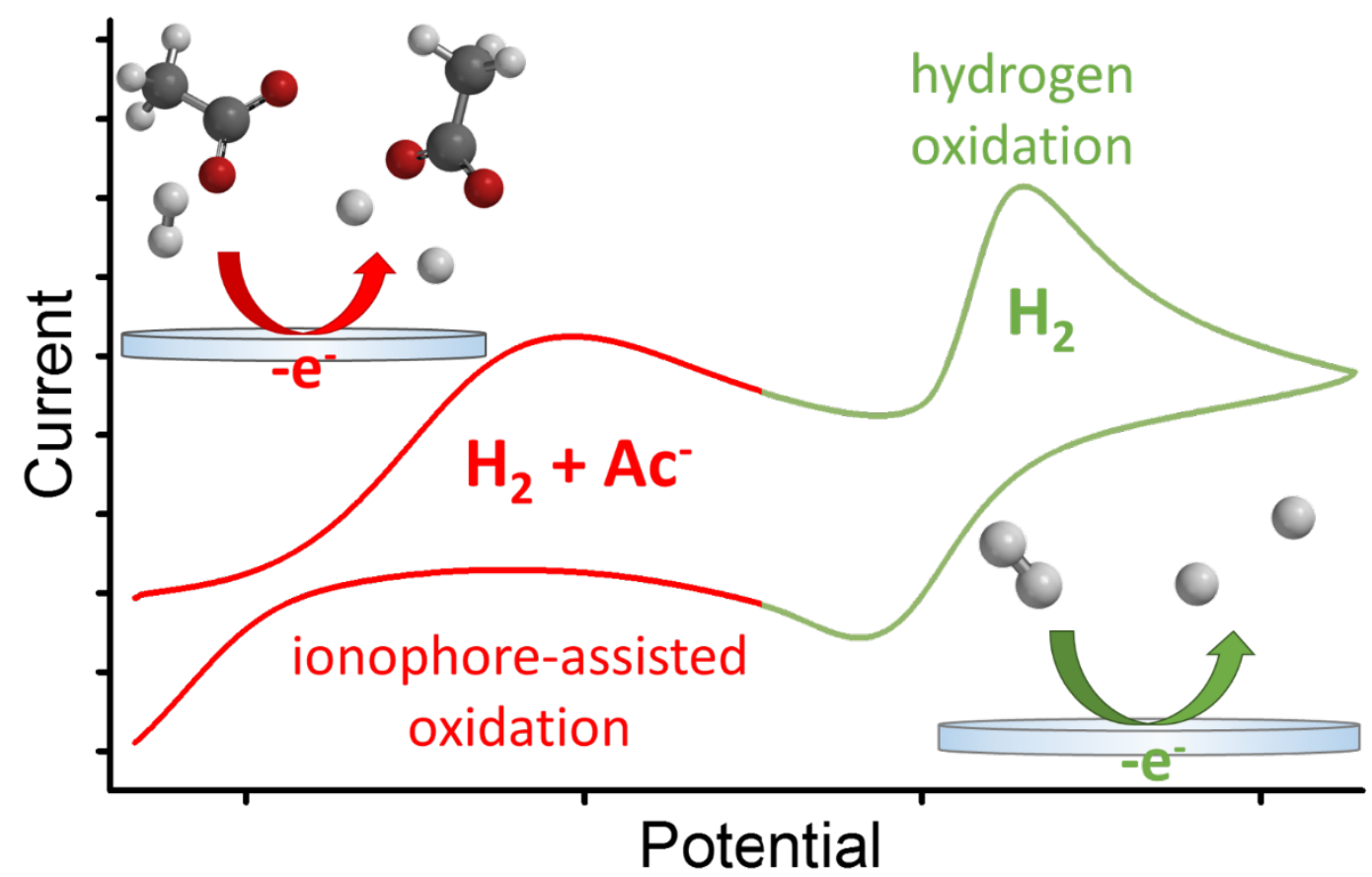

\section{Graphical Abstract text:}

An ionophore is used to bind and stabilize the ionic product of the electrochemical reaction of a neutral gas species, resulting in shifting of the reaction potential to lower values. 


\title{
Supporting Information
}

\section{Ionophore-Assisted Electrochemistry of Neutral Molecules: Oxidation of Hydrogen in an Ionic Liquid Electrolyte}

\author{
Johannes Wandt, Junqiao Lee, Damien W. M. Arrigan,* Debbie S. Silvester* \\ Curtin Institute for Functional Molecules and Interfaces, School of Molecular and Life Sciences, Curtin University, \\ GPO Box U1987, Perth, WA 6845, Australia. \\ *E-mail: D.Arrigan@curtin.edu.au; Tel: +61-8-9266-9735 \\ *Email: D.Silvester-Dean@curtin.edu.au; Tel: +61-8-9266-7148
}

\section{Table of contents}

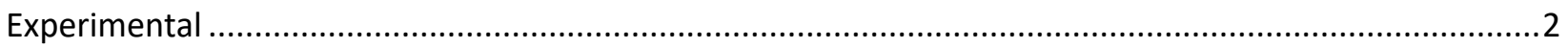

Hydrogen pre-adsorption on the platinum working electrode ….......................................................

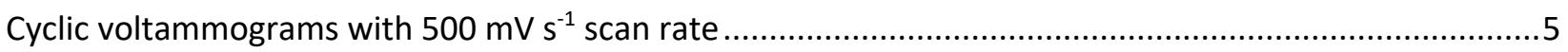

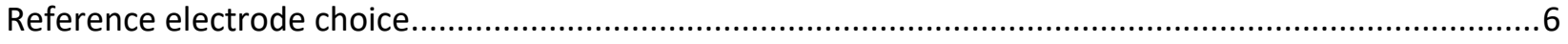

Limitation of the reductive window due to limited stability of the acetate anion ....................................

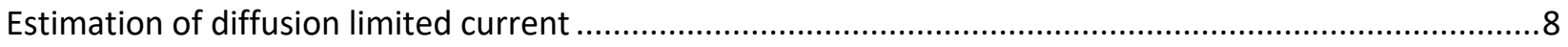

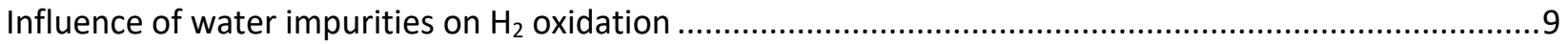

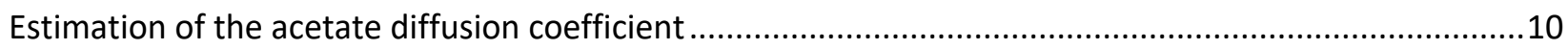

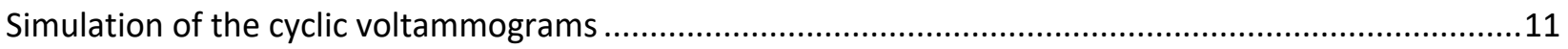

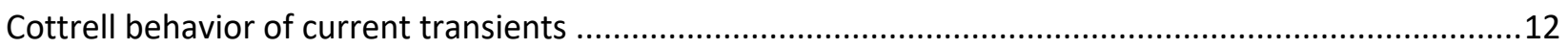

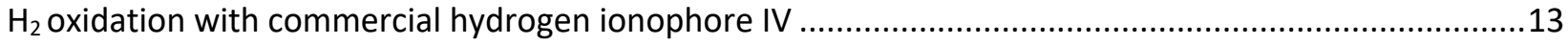

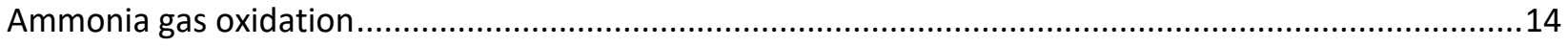

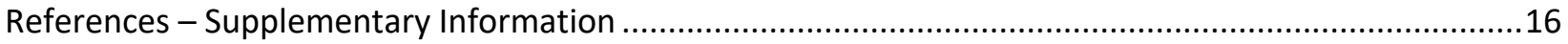




\section{Experimental}

\section{Chemical Reagents and Materials}

The room temperature ionic liquids 1-ethyl-3-methylimidazolium bis(trifluoromethylsulfonyl)imide and 1butyl-1-methylpyrrolidinium bis(trifluoromethylsulfonyl)imide (both from loLiTec GmbH, Heilbronn, Germany, at $99 \%$ ) were washed with ultrapure water (18.2 M $\Omega \mathrm{cm}$, Millipore Pty Ltd., North Ryde, NSW, Australia), to extract water-soluble impurities, then dried under dynamic vacuum at $100^{\circ} \mathrm{C}$ for three days and transferred to a nitrogen-filled glovebox (BOC gases, NSW, Australia, $\mathrm{H}_{2} \mathrm{O}<2 \mathrm{ppm}, \mathrm{O}_{2}<2 \mathrm{ppm}$ ) without contact with air. Tetrabutylammonium acetate (Sigma-Aldrich, $99.0 \%$ ) was recrystallized in acetonitrile (Sigma-Aldrich, NSW, Australia, $99.9 \%$ ). The recrystalized tetrabutylammonoum acetate and as-received hydrogen ionophore IV (Sigma Aldrich Selectrophore ${ }^{\mathrm{TM}}$ ), nonactin (ammonium ionophore I, Sigma Aldrich Selectrophore ${ }^{\mathrm{TM}}$, > $95 \%$ ) and 18-crown-6 (Sigma Aldrich, $99 \%$ ) were dried under static vacuum over calcium sulfate (Drierite, Sigma-Aldrich) at room temperature for two days and transferred to the glovebox without contact with air. Glassfiber filter paper (Whatman, Sigma-Alrich) was dried at 120 ${ }^{\circ} \mathrm{C}$ for two days and quickly transferred to the glovebox before cooling down. For the reference electrode, $\mathrm{LiFePO}_{4}$ (LFP, Clariant, Germany), $\mathrm{K}_{2} \mathrm{~S}_{2} \mathrm{O}_{8}$ (Sigma Aldrich, >99.0\% purity), polyvinylidene fluoride (PVDF, Kynar) and n-methyl-2- pyrrolidone (NMP, Sigmal Aldrich) were used as received. Lithium bis(trifluoromethylsulfonyl)imide salt (Li[NTf 2 , Sigma-Aldrich, $99.95 \%$ ) was dried at $120^{\circ} \mathrm{C}$ for three days under dynamic vacuum and transferred to the glovebox without contact to air. Microchips containing three thin-film (150 nm thick) platinum electrodes (ED-SE1- Pt, MicruX, Ovedio, Spain, diameter of working electrode $1 \mathrm{~mm}$ ) were first cleaned with acetonitrile (Sigma-Aldrich, $99.9 \%$ ), then electrochemically activated in $0.5 \mathrm{M} \mathrm{H}_{2} \mathrm{SO}_{4}(\mathrm{aq})$ by scanning the potential between -0.7 and $+0.8 \mathrm{~V}$ vs. Pt-reference electrode for 30 scans at a scan rate of $500 \mathrm{mVs}^{-1}$, rinsed with ultrapure water $(18.2 \mathrm{M} \Omega \mathrm{cm})$, and dried under dynamic vacuum for two days before transferring them to the glovebox. Ferrocene (Fluka, $98 \%$ ), decamethyl ferrocene (Sigma-Aldrich, NSW, Australia, 98\%) and acetone (Sigma-Aldrich, NSW, Australia, > 99.9 \%) for testing of the reference electrode potential were used as-received.

\section{Electrochemical experiments}

Preparation for the electrochemical experiments was carried out inside a nitrogen filled glove box, solely using rigorously dried chemicals and materials as explained above. The experimental set-up consisted of two microchips, one containing the working and counter electrodes (WE\&CE) and the other chip containing the LFP reference electrode (RE). The preparation of the LFP-reference electrodes is explained in detail elsewhere. ${ }^{1}$ The electrolyte is kept in place by a glass fiber filter paper (size $7 \times 14 \mathrm{~mm}$ ) covering both the working, counter and reference electrodes. Different electrolytes were used for the WE\&CE and the RE side: the WE\&CE electrolyte consisted of an RTIL and optionally also an ionophore; the WE electrolyte consisted of the same RTIL, no ionophore and $1 \mathrm{mM} \mathrm{Li}\left[\mathrm{NTf}_{2}\right]$ to properly define the reference potential. Of each electrolyte, about $15 \mu \mathrm{L}$ were added to the respective sides of the glass fiber filter paper and kept in place by capillary forces. Mixing of the electrolytes in the WE\&CE and RE compartments due to lateral (horizontal) diffusion (distance between WE/CE and the RE of $>5 \mathrm{~mm}$ ) of the ionophore and the Li-ions can be neglected on the time scale of the experiment. The junction potential which could potentially arise from the different Li-ion concentrations on the WE\&CE and RE side (zero vs $1 \mathrm{mM}$ ) can be neglected as discussed below.

The microchips were contained within a glass T-cell ${ }^{2}$ which has been slightly modified to improve the airtightness. Before use, the glass cell had been heated at $120^{\circ} \mathrm{C}$ for a few hours to remove residual moisture. After insertion of the microchips, the hermetically sealed glass cell was transferred from the glovebox to an aluminum Faraday cage for reduced electrical interference and connected to the gas supply. The gas 
supply system consisted of a nitrogen cylinder and a second cylinder containing either hydrogen (100 vol\%, BOC gases, NSW, Australia, $99.5 \%$ ) or ammonia (2000 ppm in nitrogen, CAC gases, NSW, Australia) and two digital flow meters. Details regarding the gas mixing system have been reported previously by our group. ${ }^{3}$ Before attaching the glass cell to the gas supply, the tubing was flushed with nitrogen for at least 30 minutes to remove residual moisture. The cell was flushed for 15 minutes with nitrogen gas (flow rate of $300 \mathrm{sccm}$ ) and evacuated under vacuum for 15 minutes to remove any residual moisture, oxygen or other trace impurities, before measuring blank cyclic voltammograms under nitrogen flow. When changing the gas composition, a rest period of ten minutes was applied before the next cyclic voltammogram was recorded; in-between consecutive cyclic voltammograms, rest periods of five minutes were applied, and the open-circuit potential was monitored to ensure full system equilibration. All electrochemical experiments were performed at laboratory room temperature (294 $\pm 1 \mathrm{~K}$ ) using a PGSTAT101 Autolab potentiostat (Eco, Chemie, Netherlands) interfaced to a PC with Nova 1.11.2 software package. 


\section{Hydrogen pre-adsorption on the platinum working electrode}

The inset to Figure S1 shows the current amplitude of the oxidative peaks for scan rates of $25 \mathrm{mVs}^{-1}$ (black, left y-axis) and $500 \mathrm{mVs}^{-1}$ (red, right y-axis) as a function of hydrogen concentration. This data is extracted from Figure 1 of the main manuscript. The peak current increases monotonously but not strictly linearly with increasing hydrogen concentration. The main panel of Figure S1 shows the peak current normalized by the hydrogen concentration. The high value for $1 \mathrm{vol}-\% \mathrm{H}_{2}$ is indicative of the contribution of preadsorbed hydrogen contributing to the oxidation current as previously observed by Sawyer and co-workers for the hydrogen oxidation on platinum electrodes in aprotic organic solvents, ${ }^{4}$ and consistent with observations for 1 vol- $\% \mathrm{H}_{2}$ in RTILs. ${ }^{5}$

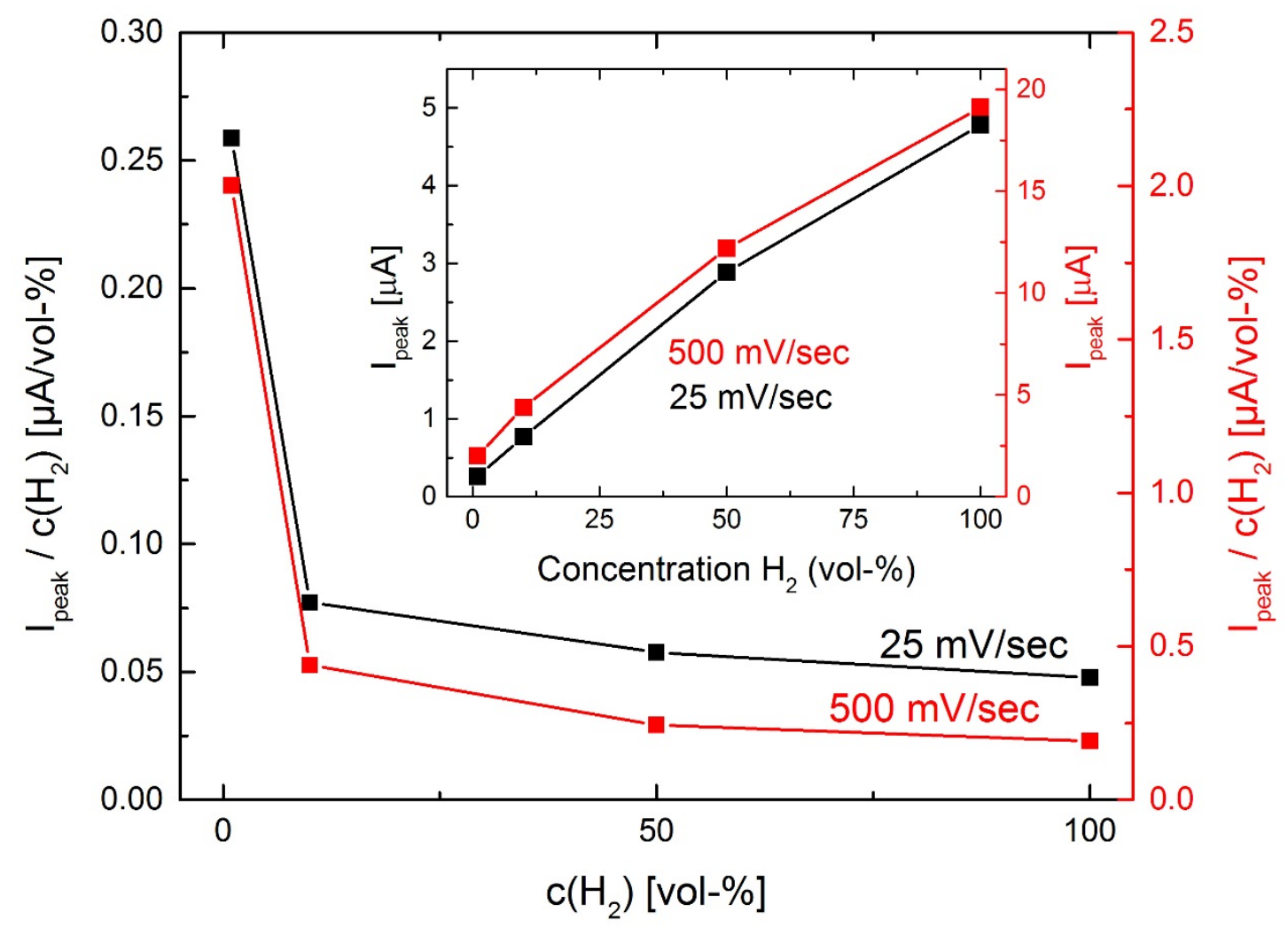

Figure S1 Peak current for hydrogen oxidation normalized by the respective hydrogen concentration. Inset: Peak current of hydrogen oxidation without normalization. 


\section{Cyclic voltammograms with $500 \mathrm{mV} \mathrm{s}^{-1}$ scan rate}

Figures S2 a and S2 b show the same experiment as Figures $1 \mathrm{a}$ and $1 \mathrm{~b}$ of the main manuscript, except the scan rate is $500 \mathrm{mVs}^{-1}$ (not $25 \mathrm{mVs}^{-1}$ ).
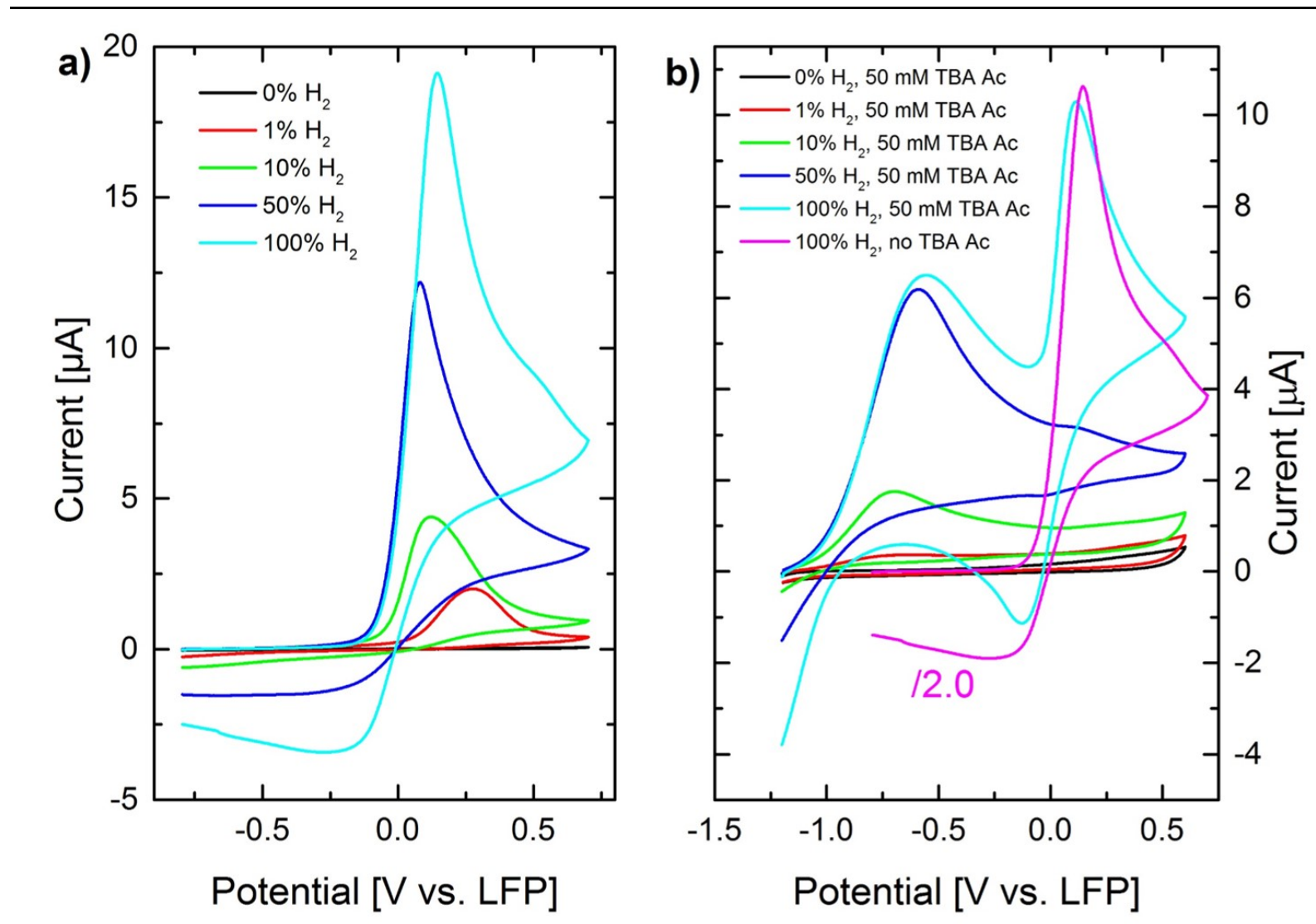

Figure S2 Cyclic voltammograms showing the hydrogen oxidation in $\left[\mathrm{C}_{2} \mathrm{mim}\right]\left[\mathrm{NTf}_{2}\right]$ in the absence (left panel) and presence (right panel) of $50 \mathrm{mM}$ TBA acetate for various hydrogen gas phase concentrations with a scan rate of $500 \mathrm{mVs}^{-1}$. 


\section{Reference electrode choice}

The concept of a lithium iron phosphate (LFP) reference electrode has been explained in detail in our previous publication. ${ }^{1}$ The main advantage of the LFP reference electrode is its simplicity, small size and stable reference potential even in the presence of oxidizing and reducing gases. The potential of the LFP reference electrode is determined by the following equilibrium

$$
\mathrm{LiFePO}_{4} \rightleftharpoons \mathrm{Li}^{+}+e^{-}+\mathrm{FePO}_{4}
$$

and only depends on the $\mathrm{Li}^{+}$-concentration in the electrolyte. In the present manuscript, a $\mathrm{Li}^{+}$concentration of $1 \mathrm{mM}$ was used for the LFP reference electrode. The potential of the LFP reference electrode used in this work was experimentally determined to be about $+10 \mathrm{mV}$ vs ferrocene. Ferrocene is frequently used as a comparable reference potential in various electrolyte systems. ${ }^{6,7}$

The stability and reproducibility of the LFP reference electrode under the experimental conditions used in this study has been confirmed by an additional experiment: After an extended series of cyclic voltammograms recorded in hydrogen atmosphere (up to $100 \%$ hydrogen concentration), the electrochemical cell was purged with nitrogen to remove all hydrogen from the electrolyte. The cell was opened and a few drops of $10 \mathrm{mM}$ decamethyl ferrocene (DMFc) dissolved in acetone were carefully added to the working electrode compartment. The cell was sealed again, purged with nitrogen and after the evaporation of the acetone, cyclic voltammograms (Figure S1 a) were recorded in the potential region containing both DMFc and hydrogen redox peaks. The first scan (black curve in Figure S3 a) shows only the DMFc peaks with a half-wave potential $\left(E_{1 / 2}\right)$ at $-515 \mathrm{mV}$ vs LFP under a nitrogen atmosphere. After introducing hydrogen, the cyclic voltammograms show the DMFc peaks with an $E_{1 / 2}$ at $-515 \mathrm{mV}$ vs LFP and additionally the broader hydrogen oxidation peak at more positive potentials. The hydrogen peaks slowly shift to more positive potentials while the DMFc position remains unchanged within $\pm 3 \mathrm{mV}$. The shift of the hydrogen oxidation peak is caused by the gradual removal of moisture (see main manuscript) which has entered the cell while injecting the 10-MeFc solution.

For this experiment, DMFc was used rather than ferrocene because the oxidation peak of the latter overlaps with hydrogen. The potential of DMFc was determined in a separate experiment (Figure S3 b) to be $-513 \mathrm{mV}$ vs ferrocene. Accordingly, the LFP reference electrode used for the experiment in Figure S1 had a potential of $+2 \mathrm{mV}(=-513 \mathrm{mV}+515 \mathrm{mv})$ vs ferrocene after an entire series of hydrogen voltammograms. This potential compares very well with the above stated potential of $+10 \mathrm{mV}$ vs ferrocene for a fresh LFP reference electrode, thus confirming the reliability of the LFP reference electrode for the experiments shown in this manuscript. This experiment also rules out the presence of a significant junction potential caused by the presence of $1 \mathrm{mM}$ Li[ $\left.\mathrm{NTf}_{2}\right]$ on the RE-side. 

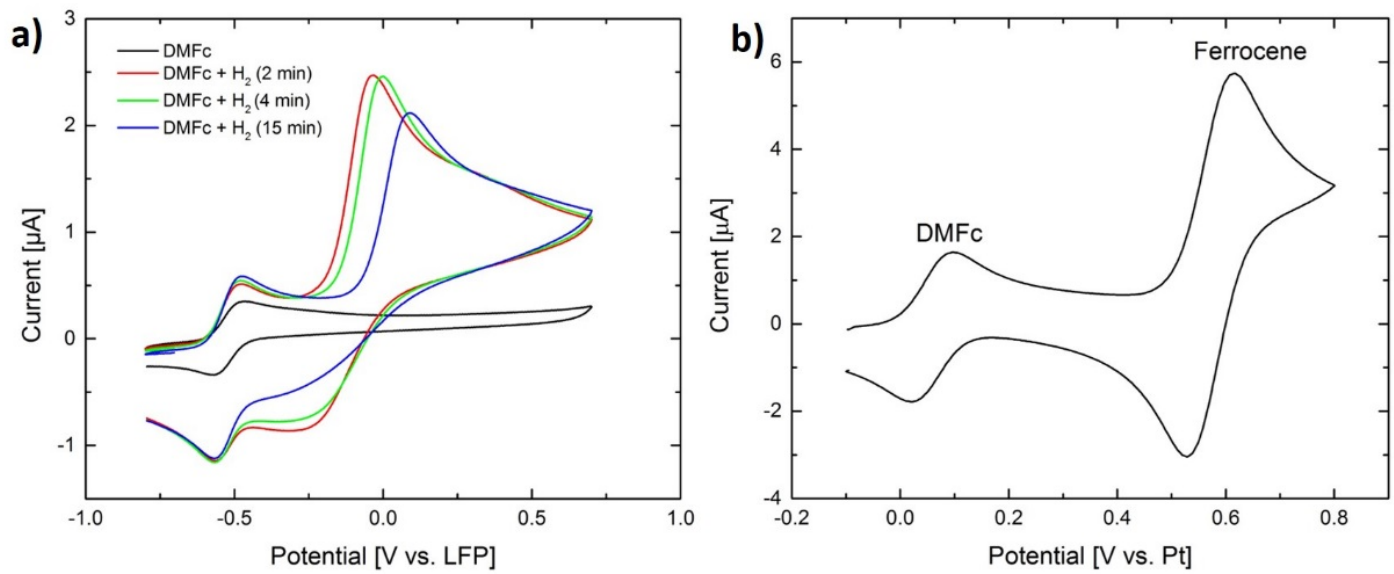

Figure S3 a) Cyclic voltammograms measured in a cell after prolonged hydrogen exposure; b) Cyclic voltammogram showing both decamethylferrocene and ferrocene.

\section{Limitation of the reductive window due to limited stability of the acetate anion}

The voltammetry shown in Figure $1 \mathrm{~b}$ of the main text was potential limited in the reductive cycle. Initial experiments showed that the onset of acetate reduction in the absence of hydrogen or protons starts at about $-1.5 \mathrm{~V}$ vs. the LFP reference electrode. During repeated scans it was shown that once this acetate reduction occurs, new features were introduced in the blank $\mathrm{CV}$, indicating that the working electrode surface is contaminated. As a result and in order to record clean CVs for hydrogen oxidation, the reductive potential range was limited. Due to this limitation it is not possible to fully analyze the reduction of the acetate-bound protons. 


\section{Estimation of diffusion limited current}

In Figure 1 of the main manuscript, the current reaches quasi-steady values at high overpotentials for hydrogen concentrations of 10 and 50 vol.-\% at a scan rate of $25 \mathrm{mV} \mathrm{s}^{-1}$. This quasi-steady state current should equal the diffusion limited current which can be estimated in a simple way assuming linear diffusion based on Fick's first law.

The equilibrium concentration of dissolved hydrogen $c_{\max }\left(\mathrm{H}_{2}\right)$ in $\left[\mathrm{C}_{2} \mathrm{mim}\right]\left[\mathrm{NTf} f_{2}\right]$, which is present at the electrolyte/gas interface, can be calculated according to

$$
c_{\max }\left(\mathrm{H}_{2}\right)=c_{\mathrm{RTIL}} \frac{p\left(\mathrm{H}_{2}\right)}{H_{a}}
$$

where $C_{\text {RTLL }}$ is the molar concentration of the ionic liquid [ $\left.\mathrm{C}_{2} \mathrm{mim}\right]\left[\mathrm{NTf}_{2}\right]\left(3.8 \mathrm{~mol} \mathrm{~L}^{-1}\right), p\left(\mathrm{H}_{2}\right)$ is the hydrogen partial pressure in the gas phase and $H_{a}$ is the respective Henry's law gas constant $(260 \mathrm{MPa})$ at $25{ }^{\circ} \mathrm{C}^{8}$ The total pressure inside the electrochemical test cell is 1 bar, therefore gas phase hydrogen concentrations of 10 and 50 vol-\% equate to $c_{\max }\left(\mathrm{H}_{2}\right)$ liquid phase (dissolved) concentrations of 0.14 and $0.70 \mathrm{mmol} \mathrm{L}^{-1}$.

Assuming a full concentration gradient (zero hydrogen concentration at the electrode/electrolyte interface), the corresponding diffusion limited steady-state current $i_{s s}$ equals

$$
i_{\mathrm{sS}}=A z_{e} F D \frac{c_{\max }\left(\mathrm{H}_{2}\right)}{d x}
$$

where $A$ is the area of the working electrode $\left(=0.79 \mathrm{~mm}^{2}\right), z_{e}$ is the number of transferred electrons per hydrogen molecule $(=2), F$ is the Faraday constant, $D$ is the diffusion coefficient of $5.5 \times 10^{-10} \mathrm{~m}^{2} \mathrm{~s}^{-1}$ for hydrogen in $\left[\mathrm{C}_{2} \mathrm{mim}\right]\left[\mathrm{NTf}_{2}\right]^{9}$ and $d x$ is the diffusion length which equals the thickness of the electrolyte soaked glass fiber filter paper of about $200 \mu \mathrm{m}$.

The resulting diffusion limited currents, $i_{s s}$, for 10 and 50 vol-\% gas phase hydrogen concentrations are 0.06 and $0.3 \mu \mathrm{A}$, respectively. These values agree within a factor of four with the measured quasi-steady-state currents of 0.025 and 1.25. This simple estimation confirms the validity of our experimental data. The remaining discrepancy might be caused by errors in the Henry's law gas constant, the diffusion coefficient and especially the fact that the surface of the electrolyte film contained within the glass fiber filter paper shows a significant roughness on the microscopic scale which enhances the crossing of hydrogen into the liquid phase and reduces the diffusion length. 


\section{Influence of water impurities on $\mathrm{H}_{2}$ oxidation}

Figure S4 shows the influence of the water content on the hydrogen oxidation potential in two hydrophobic room temperature ionic liquids. The water content increases in the following order: black < red < green < blue. The black curves in Figure S3 show cyclic voltammograms for hydrogen oxidation measured under the "high purity" conditions used for all experiments of this study with a dried and purified RTIL (see experimental for details). For the red curves in Figure S3, the purified RTIL was replaced by an as-received RTIL which was only evacuated at room temperature for 15 minutes directly before recording the cyclic voltammograms. For the green curve, the high purity nitrogen for flushing of the electrochemical cell was replaced by houseline nitrogen which is known to contain a significant water content. For the blue curve, the nitrogen stream was bubbled through a water column.

It is evident that for both ionic liquids shown in Figure S4, the hydrogen oxidation potential decreases with increasing water content. A closer look at Figures $\mathrm{S} 4 \mathrm{a}$ and $\mathrm{b}$ reveals that the hydrogen oxidation potentials are about $200 \mathrm{mV}$ lower for [ $\left.\mathrm{C}_{2} \mathrm{mim}\right]\left[\mathrm{NTf}_{2}\right]$ in comparison to $\left[\mathrm{C}_{4} \mathrm{mpyrr}\right]\left[\mathrm{NTf}_{2}\right]$. Both ionic liquids contain the same anion, therefore the stabilization of the protons can be considered to be very similar in these two RTILs. The lower oxidation potential in $\left[\mathrm{C}_{2} \mathrm{mim}\right]\left[\mathrm{NTf}_{2}\right]$ is more likely to be caused by the lower hydrophobicity of [ $\left.\mathrm{C}_{2} \mathrm{mim}\right]\left[\mathrm{NTf}_{2}\right]$ in comparison to $\left[\mathrm{C}_{4} \mathrm{mpyrr}\right]\left[\mathrm{NTf}_{2}\right],{ }^{10,11}$ resulting in a higher residual water content under similar external conditions. ${ }^{12}$
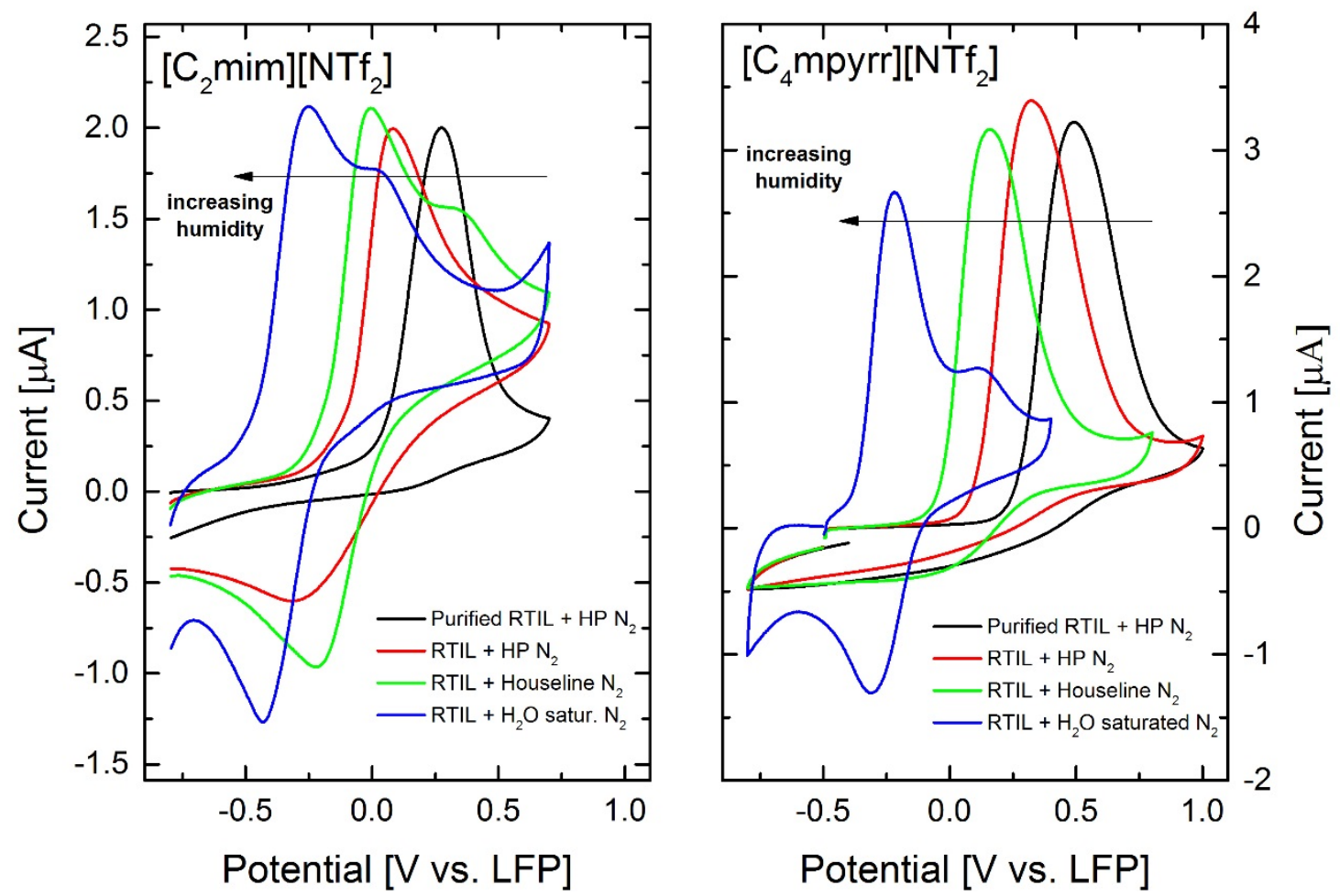

Figure S4 Cyclic voltammograms showing hydrogen oxidation (1 vol-\%) in (a) $\left[\mathrm{C}_{2} \mathrm{mim}\right]\left[\mathrm{NTf}_{2}\right]$ or (b) [C4mim] $\left[\mathrm{NTf}_{2}\right.$ ] with scan rates of $500 \mathrm{mVs}^{-1}$ at different levels of humidity. 


\section{Estimation of the acetate diffusion coefficient}

Based on the cyclic voltammograms of the actetate-assisted $\mathrm{H}_{2}$ oxidation with $\mathrm{H}_{2}$ concentrations of 100 vol-\% presented in Figure $1 \mathrm{~b}$ (main manuscript, scan rate of $25 \mathrm{mV} \mathrm{s}^{-1}$ ) and Figure $\mathrm{S} 1 \mathrm{~b}$ (supporting information, scan rate of $500 \mathrm{mV} \mathrm{s}^{-1}$ ), it is possible to estimate the diffusion coefficient for acetate in $\left[\mathrm{C}_{2} \mathrm{mim}\right]\left[\mathrm{NTf}_{2}\right]$.

The determination of the acetate diffusion coefficient is based on the fact that the current at potentials below the onset of the unassisted $\mathrm{H}_{2}$ oxidation (e.g. below $-0.1 \mathrm{~V}$ vs LFP in Figure $1 \mathrm{~b}$ ) is limited by the acetate diffusion from the bulk electrolyte towards the electrode surface. Integration of the cyclic voltammogram from -1.2 to $-0.1 \mathrm{~V}$ gives a charge of $47 \mu$ As which equals $4.9 \times 10^{10}$ moles of acetate (considering a 1/1 ratio for $\mathrm{e}^{-} / \mathrm{Ac}^{-}$, see equation 3 main manuscript). Note that the integration in the above stated potential region also includes a small portion at the beginning of the scan, where the HOR is limited kinetically rather than by the diffusional supply of acetate. Due to the relatively small current, the corresponding error can be neglected.

We now assume that the entire amount of acetate comes from the electrolyte volume above the electrode area $\left(A=0.79 \mathrm{~mm}^{2}\right)$ within the diffusion length ${ }^{13} x$ of

$$
x=\sqrt{D_{\mathrm{Ac}} t}
$$

where $D_{\mathrm{Ac}}$ is the acetate diffusion coefficient and $t$ is the time. The diffusion length, $x$, can be calculated from the molar amount of acetate and the bulk concentration $\left(c\left(A c^{-}\right)=50 \mathrm{mM}\right)$ to equal $12.5 \mu \mathrm{m}$, which is significantly less than the thickness of the electrolyte film $(200 \mu \mathrm{m})$. The time, $t$, can be calculated based on the potential range of $1.1 \mathrm{~V}(=-1.2 \mathrm{~V}-(-0.1 \mathrm{~V}))$ and the scan rate $\left(25 \mathrm{mVs}^{-1}\right)$ to equal $44 \mathrm{~s}$. Solving equation (3) for $D_{\mathrm{Ac}}$ and inserting values for $x$ and $t$ gives a diffusion coefficient of $3.5 \times 10^{-8} \mathrm{~cm}^{2} \mathrm{~s}^{1}$.

For the cyclic voltammogram recorded with a scan rate of $500 \mathrm{mVs}^{-1}$, the integrated charge only equals 8.7 $\mu$ As. The corresponding time $t$ is $2.2 \mathrm{~s}$ which gives an acetate diffusion coefficient of $2.2 \times 10^{-8} \mathrm{~cm}^{2} \mathrm{~s}^{-1}$. The values obtained of the two different scan rates agree very well, so that an averaged value of $3 \times$ $10^{-8} \mathrm{~cm}^{2} \mathrm{~s}^{1}$ can be estimated for the acetate diffusion coefficient. 


\section{Simulation of the cyclic voltammograms}
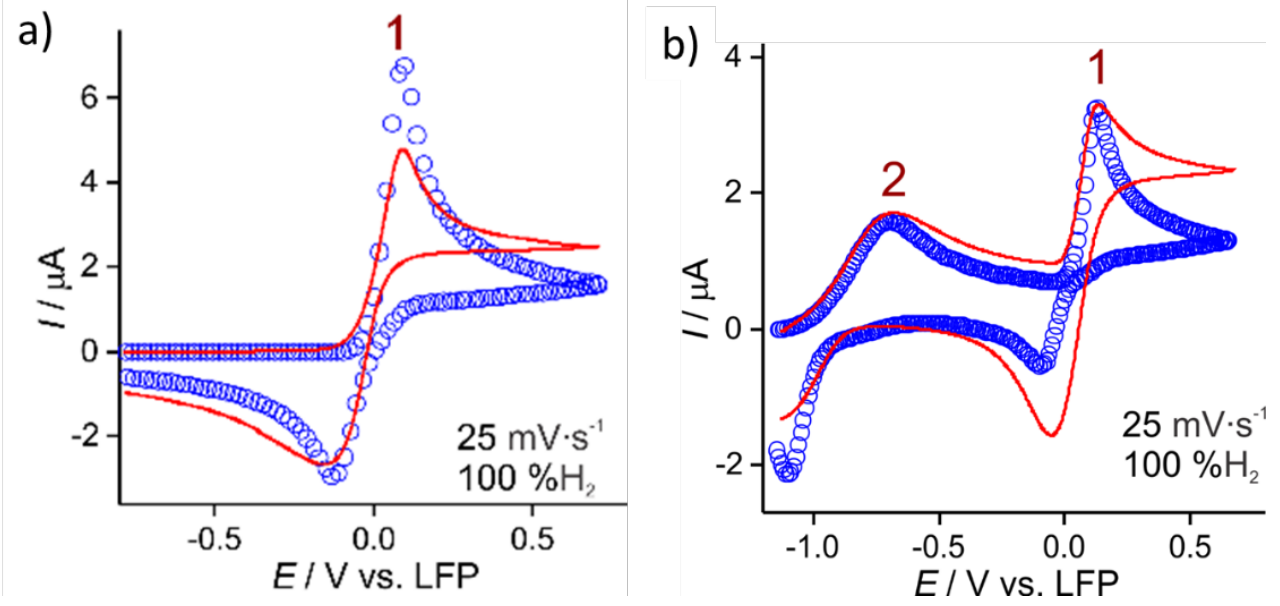

Figure S5 Simulated (0) and experimental (-) cyclic voltammograms of 1, 10, 50, and $100 \%$ vol. hydrogen gas in $\left[\mathrm{C}_{2} \mathrm{mim}\right]\left[\mathrm{NTf}_{2}\right]$ at 25 and $500 \mathrm{mVs}^{-1}$, in the absence (a) and presence of $50 \mathrm{mM}$ of acetate. The peaks associated to the reaction equations (1) and ( 3 ) in the main text are numbered accordingly. The simulation was performed using DigiElch 8.0.

Figure S5 shows a simulation of the cyclic voltammogram in the absence and presence of the acetateionophore. The simulation was carried out with the DigiElch 8.0 program $^{14}$ using the Semi-Infinite $1 D$ diffusion model (i.e. where planar diffusion dominates). Electrode and electrolyte properties (e.g. resistance and double layer capacity), hydrogen solubility, diffusion coefficient, and kinetic rate constants of the anodic and cathodic reactions were taken from previous studies. ${ }^{15,16}$ For the acetate-ionophore, the above derived diffusion coefficient of $D=3 \times 10^{-8} \mathrm{~cm}^{2} \mathrm{~s}^{1}$ was used. The hydrogen oxidation forming free protons (peak 1 in Figure S5) was simulated using a simple E step, the acetate-assisted hydrogen oxidation (peak 2 in Figure S5) was simulated by a combination of an electrochemical and a very rapid chemical step. We note that the E step is a simplification to enable us to model the voltammetry. A more complex 4-step mechanism was proposed by Tang et al. ${ }^{[7]}$ The simulation of the acetate-assisted hydrogen oxidation captures all relevant processes, namely i) hydrogen and acetate diffusion towards the electrode surface and ii) the combination of an electrochemical and chemical reaction step and can reproduce the experimental data fairly well, thus validating the acetate diffusion coefficient. Note that the reduced complexity of the DigiElch simulation does not allow any detailed insights on the exact reaction mechanisms on a molecular level. 


\section{Cottrell behavior of current transients}

Figure $\mathrm{S} 6$ shows the experimental current transients recorded in the presence of $50 \mathrm{mM}$ TBA Ac (same data as Figure $2 \mathrm{~b}$, main manuscript) together with calculated currents based on the Cottrell equation:

$$
i=\frac{z_{e} F A c_{j}^{0} \sqrt{D_{j}}}{\sqrt{\pi} \sqrt{t}}
$$

with $z_{e}=2, A=0.79 \mathrm{~mm}^{2}, c^{0}=1.4 \mathrm{mmol} \mathrm{L}^{-1} \times p\left(\mathrm{H}_{2}\right)_{\text {rel. }} / 100 \%$ where $p\left(\mathrm{H}_{2}\right)_{\text {rel. }}$ is the hydrogen gas phase concentration in vol- $\%$ and $D$ is the $\mathrm{H}_{2}$ diffusion coefficient in $\left[\mathrm{C}_{2} \mathrm{mim}\right]\left[\mathrm{NTf}_{2}\right]$ of $5.5 \times 10^{-10} \mathrm{~m}^{2} \mathrm{~s}^{-1}$.
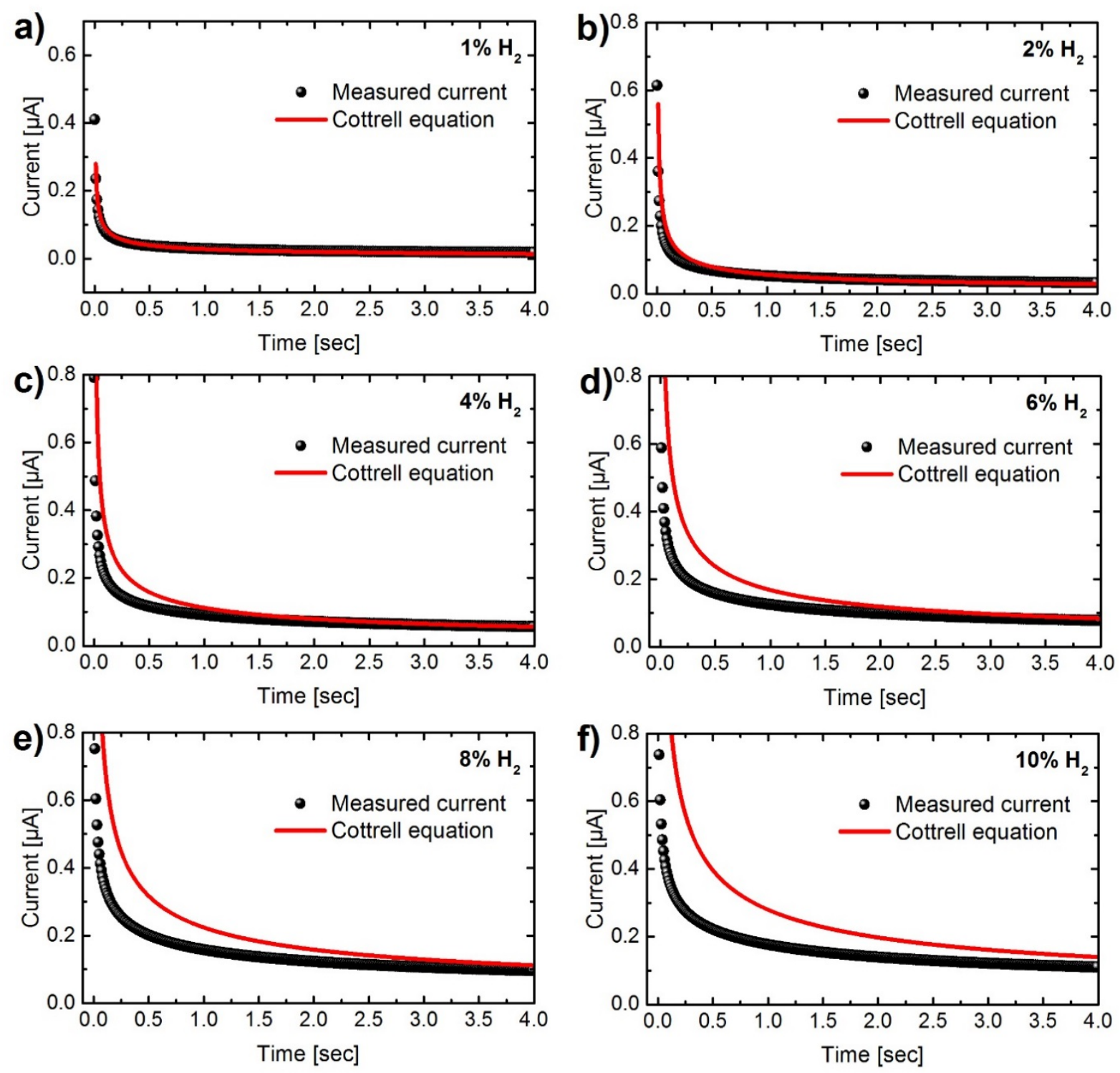

Figure $\mathrm{S} 6$ Black dots: $\mathrm{H}_{2}$ oxidation current transients measured after stepping the potential from -1.2 to $0.35 \mathrm{~V}$ vs LFP in a $\left[\mathrm{C}_{2} \mathrm{mim}\right]\left[\mathrm{NTf}_{2}\right]$ electrolyte; red lines: Calculated current based on the Cottrell equation. 


\section{$\mathrm{H}_{2}$ oxidation with commercial hydrogen ionophore IV}

Figure $\mathrm{S} 7$ shows the HOR in $\left[\mathrm{C}_{2} \mathrm{mim}\right]\left[\mathrm{NTf}_{2}\right]$ in the presence of $1 \mathrm{mM}$ of the commercial hydrogen ionophore IV (Sigma Aldrich Selectrophore ${ }^{\mathrm{TM}}$ ). The hydrogen ionophore IV contains a pyridine ring for proton binding and a long alkyl chain for solubilisation in membranes. The low polarity of the hydrogen ionophore IV limited the solubility in $\left[\mathrm{C}_{2} \mathrm{mim}\right]\left[\mathrm{NTf}_{2}\right]$ so that ionophore concentrations above $1 \mathrm{mM}$ could not be tested. The cyclic voltammograms obtained with hydrogen ionophore IV (Figure S7 a and b) are qualitatively similar to those with the acetate ionophore, but the current of the first ionophore-assisted oxidation peak is very low. This is a direct consequence of the low bulk concentration and slow diffusion (large size) of the hydrogen ionophore IV which causes its rapid depletion at the electrode surface.

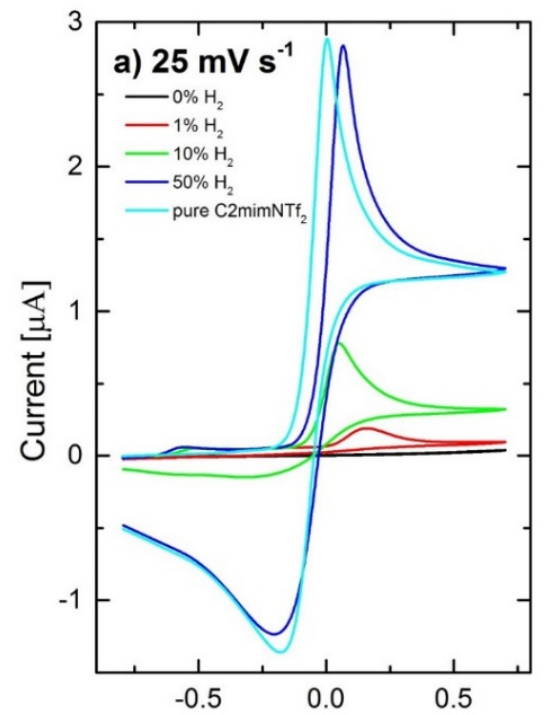

Potential [V vs. LFP]

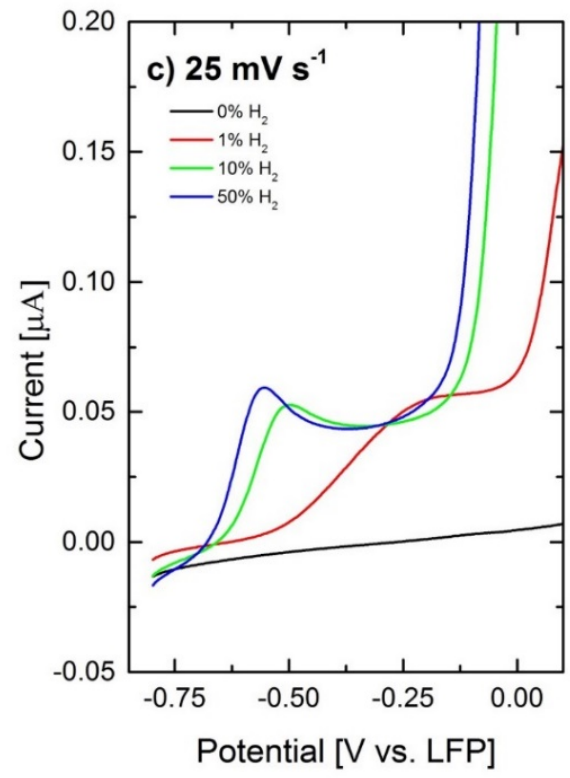

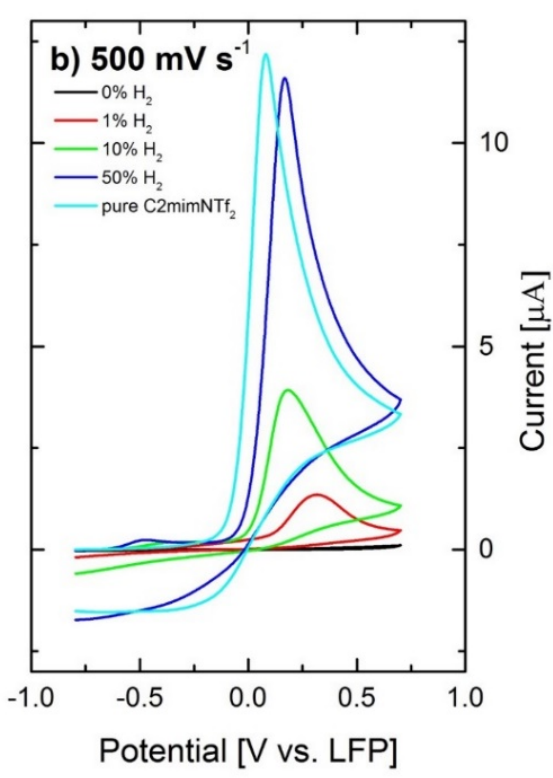

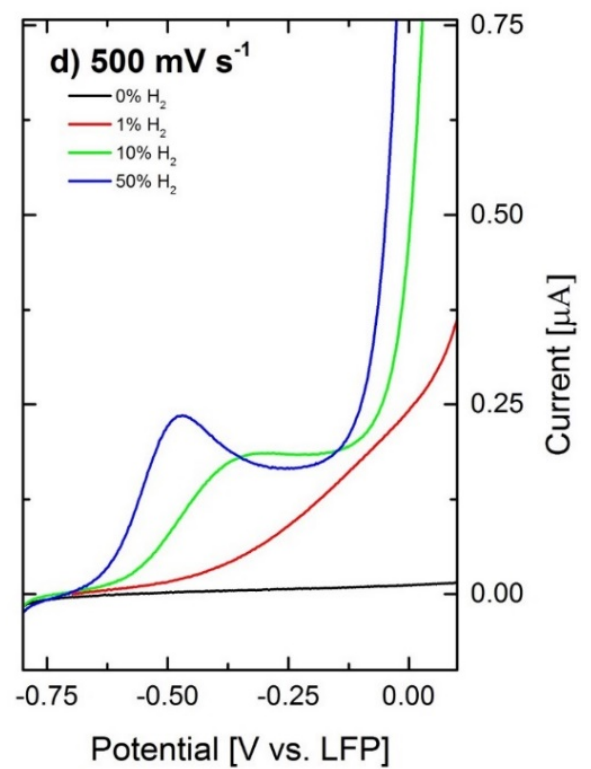

Figure S7 a) and b): Cyclic voltammograms showing hydrogen oxidation in [ $\left.\mathrm{C}_{2} \mathrm{mim}\right]\left[\mathrm{NTf}_{2}\right]$ in the presence of $1 \mathrm{mM}$ hydrogen ionophore IV for various hydrogen gas phase concentrations with scan rates of $25 \mathrm{mVs}^{-}$ ${ }^{1}$ and $500 \mathrm{mVs}^{-1}$; $\mathrm{c}$ and d) Enlarged views of the potential region containing the oxidation peaks belonging to ionophore-assisted $\mathrm{H}_{2}$ oxidation. 


\section{Ammonia gas oxidation}

Figure S8a shows the cyclic voltammogram of $1,000 \mathrm{ppm}$ ammonia $\left(\mathrm{NH}_{3}\right)$ in pure $\left[\mathrm{C}_{2} \mathrm{mim}\right]\left[\mathrm{NTf}_{2}\right]$ with a scan rate of $500 \mathrm{mVs}^{-1}$. The shape of the voltammogram agrees very well with literature reports. ${ }^{3,17,18}$ In the first oxidative scan, there is broad oxidation peak which can be assigned to the oxidation of ammonia according to

$$
\mathrm{NH}_{3} \rightarrow 0.5 \mathrm{~N}_{2}+3 \mathrm{H}^{+}+3 e^{-}
$$

followed by a chemical reaction between the generated protons and excess ammonia, forming ammonium ions

$$
\mathrm{H}^{+}+\mathrm{NH}_{3} \rightarrow \mathrm{NH}_{4}^{+}
$$

On the reductive scan, ammonium can be reduced forming adsorbed hydrogen

$$
\mathrm{NH}_{4}^{+}+e^{-}+\mathrm{NH}_{3} \rightarrow 0.5 \mathrm{H}_{2}+\mathrm{NH}_{3}
$$

On the second oxidative scan a new oxidative peak appears at $-0.9 \mathrm{~V}$ vs LFP which is not present in the first oxidative scan. This peak can be assigned to the electrochemical oxidation of adsorbed hydrogen formed in reaction (S7)

$$
\mathrm{H}_{2}+2 \mathrm{NH}_{3} \rightarrow 2 \mathrm{NH}_{4}^{+}+2 e^{-}
$$
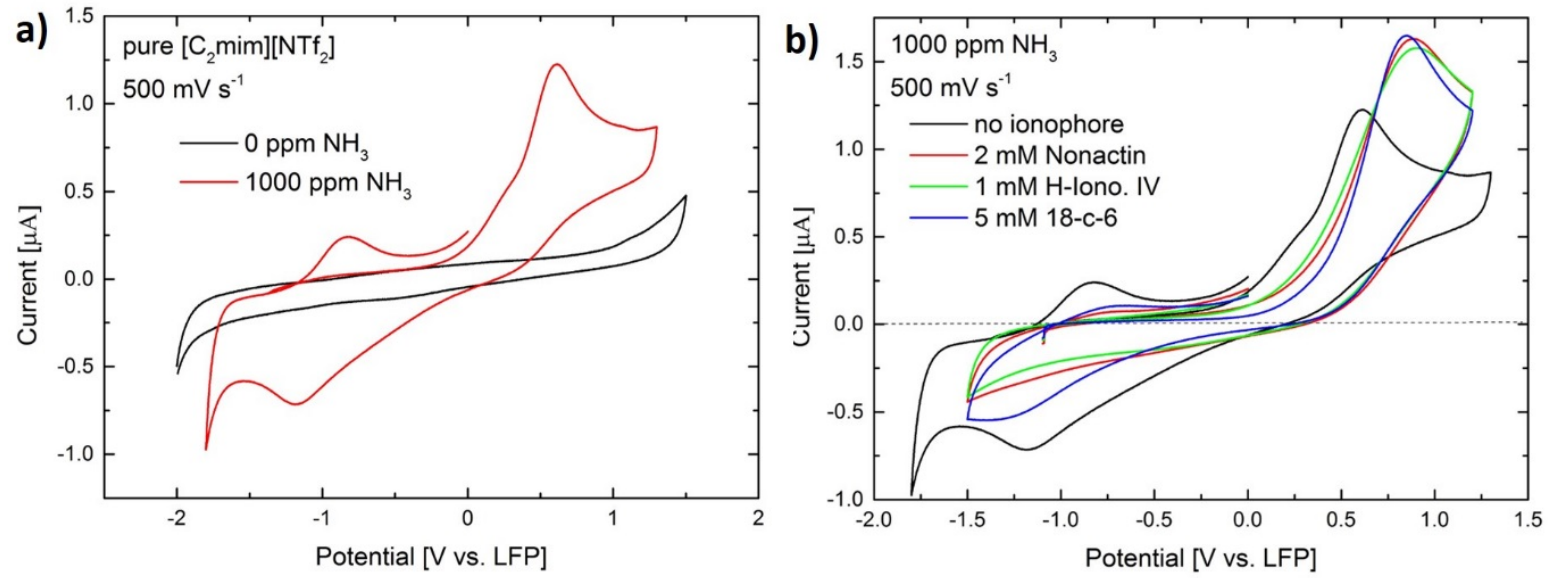

Figure S8 Cyclic voltammograms showing the ammonia oxidation $(1000 \mathrm{ppm})$ in $\left[\mathrm{C}_{2} \mathrm{mim}\right]\left[\mathrm{NTf} \mathrm{f}_{2}\right]$ in the absence (left panel) and presence (right panel) of various ionophores at a scan rate of $500 \mathrm{mVs}^{-1}$.

Figure S8b shows ammonia oxidation in the presence of three different ionophores. For all ionophores the maximum viable concentration (see legend in Figure S8 b) was used. Hydrogen ionophore IV was already described in the previous section and can bind to protons via the amine group in the pyridine ring. Nonactin is a naturally occurring macrocyclic molecule which contains ether and ester groups which is known to complex ammonium ions via hydrogen bonds. ${ }^{19-21}$ The cyclic polyether 18 -crown- 6 also contains 
a moiety which can bind both ammonium ions ${ }^{22-24}$ and because of the structural flexibility of the polyetherring also the much smaller protons and oxonium-ions. ${ }^{25-29}$

The potential window for the cyclic voltammograms in the presence of ionophores had to be restricted because of their smaller electrochemical stability window as determined by blank measurements. The cyclic voltammograms look similar for the three ionophores. The oxidation peak is shifted slightly to higher potentials and shows a higher peak current. The reduction peak and the second oxidation peak are both depressed in the presence of the ionophores. Despite these minor differences, it is evident that the presence of the ionophores does not seem to have a profound impact on ammonia oxidation, as least in comparison to acetate-assisted hydrogen oxidation. The likely reason is the more complex reaction mechanism of the ammonia oxidation. To the best of our knowledge, the exact mechanistic steps involved in electrochemical ammonia oxidation (reaction S5) in aprotic electrolytes is uncertain. In alkaline aqueous media, ammonia oxidation on a platinum electrode occurs in several consecutive oxidation steps of adsorbed $\mathrm{NH}_{\mathrm{x}}$-species. ${ }^{30}$ At high current densities, the final step is the dimerization of two fully deprotonated $\mathrm{N}$-atoms from the platinum surface to form the dinitrogen molecule. At least at high current densities, this dimerization reaction is believed to be the rate determining step in alkaline aqueous media. ${ }^{31}$ If a reaction like the nitrogen dimerization is rate determining, it is easily conceivable that ionophores which bind either protons or ammonium ions cannot significantly shift the oxidation potential. This might mean that the ionophore-concept may be reserved for more simple electrochemical reactions where the ionic reaction product is formed in the rate-determining step. 


\section{References - Supplementary Information}

(1) Wandt, J.; Lee, J.; Arrigan, D. W. M.; Silvester, D. S. A Lithium Iron Phosphate Reference Electrode for Ionic Liquid Electrolytes. Electrochem. commun. 2018, 93 (June), 148-151.

(2) Lee, J.; Murugappan, K.; Arrigan, D. W. M.; Silvester, D. S. Oxygen Reduction Voltammetry on Platinum Macrodisk and Screen-Printed Electrodes in Ionic Liquids: Reaction of the Electrogenerated Superoxide Species with Compounds Used in the Paste of Pt Screen-Printed Electrodes? Electrochim. Acta 2013, 101, 158-168.

(3) Hussain, G.; Silvester, D. S. Detection of Sub-Ppm Concentrations of Ammonia in an lonic Liquid: Enhanced Current Density Using "Filled" Recessed Microarrays. Anal. Chem. 2016, 88 (24), 1245312460.

(4) Barrette, W. C.; Sawyer, D. T. Determination of Dissolved Hydrogen and Effects of Media and Electrode Materials on the Electrochemical Oxidation of Molecular Hydrogen. Anal. Chem. 1984, 56 (4), 653-657.

(5) Tang, Y.; He, J.; Gao, X.; Yang, T.; Zeng, X. Continuous Amperometric Hydrogen Gas Sensing in lonic Liquids. Analyst 2018, 143, 4136-4146.

(6) Lewandowski, A.; Waligora, L.; Galinski, M. Ferrocene as a Reference Redox Couple for Aprotic lonic Liquids. Electroanalysis 2009, 21 (20), 2221-2227.

(7) Zhang, J.; Bond, A. M. Conditions Required To Achieve the Apparent Equivalence of Adhered Solidand Solution-Phase Voltammetry for Ferrocene and Other Redox-Active Solids in lonic Liquids. Anal. Chem. 2003, 75 (11), 2694-2702.

(8) Lei, Z.; Dai, C.; Chen, B. Gas Solubility in lonic Liquids. Chem. Rev. 2014, 114 (2), 1289-1326.

(9) Silvester, D. S.; Ward, K. R.; Aldous, L.; Hardacre, C.; Compton, R. G. The Electrochemical Oxidation of Hydrogen at Activated Platinum Electrodes in Room Temperature Ionic Liquids as Solvents. J. Electroanal. Chem. 2008, 618 (1-2), 53-60.

(10) Freire, M. G.; Neves, C. M. S. S.; Carvalho, P. J.; Gardas, R. L.; Fernandes, A. M.; Marrucho, I. M.; Santos, L.; Coutinho, J. A. P. Mutual Solubilities of Water and Hydrophobic Ionic Liquids. J. Phys. Chem. B 2007, 111, 13082-13089.

(11) Freire, M. G.; Carvalho, P. J.; Gardas, R. L.; Marrucho, I. M.; Santos, L.; Coutinho, A. P. Mutual Solubilities of Water and the [Cnmim ][Tf2N] Hydrophobic lonic Liquids. J. Phys. Chem. B 2008, 112, 1604-1610.

Mahony, A. M. O.; Silvester, D. S.; Aldous, L.; Hardacre, C.; Compton, R. G. Effect of Water on the Electrochemical Window and Potential Limits of Room-Temperature lonic Liquids Effect of Water on the Electrochemical Window and Potential Limits of Room-Temperature Ionic Liquids. Engineering 2008, 2884-2891.

(13) Krewer, U.; Fridolin, R.; Harinath, E.; Braatz, R. D.; Bed, B.; Findeisen, R. Review - Dynamic Models of Li-Ion Batteries for Diagnosis and Operation : A Review and Perspective. J. Electrochem. Soc. 2018, 165 (16), 3656-3673.

(14) DigiElch Electrochemical Simulation Software 2018 (Gamry Instruments: Warminster, PA). Available at: https://www.Gamry.Com/.

(15) Kang, C.; Lee, J.; Silvester, D. S. Electroreduction of 2,4,6-Trinitrotoluene in Room Temperature lonic Liquids: Evidence of an EC 2 Mechanism. J. Phys. Chem. C 2016, 120 (20), 10997-11005.

(16) Meng, Y.; Aldous, L.; Belding, R.; Compton, R. G. The Hydrogen Evolution Reaction in a Room Temperature Ionic Liquid : Mechanism and Electrocatalyst Trends W. Phys. Chem. Chem. Phys. 2012, 2012 (14), 5222-5228.

(17) Buzzeo, M. C.; Giovanelli, D.; Lawrence, N. S.; Hardacre, C.; Seddon, K. R.; Compton, R. G. Elucidation of the Electrochemical Oxidation Pathway of Ammonia in Dimethylformamide and the Room Temperature Ionic Liquid, 1-Ethyl-3-Methylimidazolium Bis(Trifluoromethylsulfonyl)Imide. Electroanalysis 2004, 16 (11), 888-896.

(18) Ji, X.; Silvester, D. S.; Aldous, L.; Hardacre, C.; Compton, R. G. Mechanistic Studies of the Electro- 
Oxidation Pathway of Ammonia in Several Room-Temperature lonic Liquids. J. Phys. Chem. C 2007, 111 (26), 9562-9572.

(19) Pioda, L. A. R.; Wachter, H. A.; Dohner, R. E.; Simon, W. Komplexe von Nonactin Und Monactin Mit Natrium-, Kalium- Und Ammonium-Ionen. Helv. Chim. Acta 1967, 50 (5), 1373-1376.

(20) Suzuki, K.; Siswanta, D.; Otsuka, T.; Amano, T.; Ikeda, T.; Hisamoto, H.; Yoshihara, R.; Ohba, S. Design and Synthesis of a More Highly Selective Ammonium lonophore than Nonactin and Its Application as an lon-Sensing Component for an lon-Selective Electrode. Anal. Chem. 2000, 72 (10), 2200-2205.

(21) Chin, J.; Oh, J.; Jon, S. Y.; Park, S. H.; Walsdorff, C.; Stranix, B.; Ghoussoub, A.; Lee, S. J.; Jei Chung, H.; Park, S. M.; et al. Tuning and Dissecting Electronic and Steric Effects in Ammonium Receptors: Nonactin vs Artificial Receptors. J. Am. Chem. Soc. 2002, 124 (19), 5374-5379.

(22) Hasani, M.; Shamsipur, M. Conductance Study of the Thermodynamics of Ammonium Ion Complexes with Several Crown Ethers in Acetonitrile Solution. J. Solution Chem. 1994, 23 (6), 721734.

(23) Buschmann, H. J.; Schollmeyer, E.; Mutihac, L. Complexation of the Ammonium lon by 18-Crown-6 in Different Solvents and by Noncyclic Ligands, Crown Ethers and Cryptands in Methanol. Supramol. Sci. 1998, 5 (1-2), 139-142.

(24) Liou, C.; Brodbelt, J. S. Comparison of Gas-Phase Proton and Ammonium Ion Affinities of Crown Ethers and Related Acyclic Analogs. J. Am. Chem. Soc. 1992, 114 (14), 6761-6764.

(25) Sharma, R. B.; Blades, A. T.; Kebarle, P. Protonation of Polyethers, Glymes. J. Am. Chem. Soc. 1984, 106 (12), 510-516.

(26) Buschmann, H. J. Complexation of Protons by Macrocyclic Polyethers in Acetonitrile. Polyhedron 1987, 6 (6), 1469-1472.

(27) Buschmann, H. J. Complexation of $\mathrm{H}+$ and $\mathrm{D}+$ by Crown Ethers in Propylene Carbonate. Polyhedron 1992, 11 (5), 559-561.

(28) Kříž, J.; Dybal, J.; Makrlík, E.; Budka, J. Interaction of Hydronium lon with Dibenzo-18-Crown-6: NMR, IR, and Theoretical Study. J. Phys. Chem. A 2008, 112 (41), 10236-10243.

(29) Marin, T. W.; Shkrob, I. A.; Dietz, M. L. Hydrogen-Bonding Interactions and Protic Equilibria in RoomTemperature Ionic Liquids Containing Crown Ethers. J. Phys. Chem. B 2011, 115 (14), 3912-3918.

(30) Bunce, N. J.; Bejan, D. Mechanism of Electrochemical Oxidation of Ammonia. Electrochim. Acta 2011, 56 (24), 8085-8093.

(31) Oswin, H. G.; Salomon, M. THE Anodic Oxidation of Ammonia at Platinum Black Electrodes in Aqueous KOH Electrolyte. Can. J. Chem. 1963, 41, 1686-1694. 